\title{
PASAJEROS DEL PODER PROPIETARIO. LA SOCIEDAD EXPLOTADORA DE TIERRA DEL FUEGO Y LA BIOPOLÍTICA ESTANCIERA (1890-1920)
}

JOAQUÍN BASCOPÉ JULIO

\begin{abstract}
RESUMEN
A inicios de siglo XX el negocio ovejero en Patagonia meridional había adquirido la forma de un gigantesco imperio organizado según los modernos criterios de producción británicos. La condición operativa de dicho imperio fue la producción de un desierto biopolítico que evacuó no sólo la competencia -ganadería pionera- o las jurisdicciones nacionales, sino toda forma viviente que obstruyese los flujos mercantiles, animales y humanos bajo su control. No obstante, la misma forma de este poder propietario, la estancia con sus rasgos post-industriales, permitió la emergencia de otras formas de circulación por el desierto, de otros pasajeros, que desviaron o detuvieron, al menos parcialmente, los engranajes de la máquina estanciera.
\end{abstract}

PALABRAS CLAVE: Historia estanciera, biopolítica, nomadismo obrero.

PASSENGERS OF LANDOWNER'S POWER.

THE SOCIEDAD EXPLOTADORA DE TIERRA DEL FUEGO
AND ESTANCIA'S BIOPOLITICS (1890-1920)

ABSTRACT

In the early 20th century the Patagonian sheep-farming business becomes an enormous empire following the British forms of production. The eradication not only of national sovereignties or other sheep-farmers challenged it, but of any living form obstructing goods, animals and men fluxes under his control, was the biopolitic desert necessary to landowner power. These hegemonic condition, with the post-industrial estancia as reference, allowed, however, different ways of "crossing the desert", subversive modes of being a passenger in it, that have partially interrupted the sheep-farmer's machine performance.

KEYWORDS: Estancia's history, biopolitics, nomadic workers.

\footnotetext{
* Escuela de Altos Estudios en Ciencias Sociales (EHESS), Paris, Francia. Laboratorio de Desclasificación Comparada (LDC). joaquinbascope@yahoo.com.ar
} 
Los cierros interminables guardan dentro de los alambradas piños enormes de ganado lanar. Por ninguna parte aparecen construcciones o cuidadores y ovejeros. Hace ya una hora que corremos por los campos de "Caleta Josefina"; nuestro auto es el único ser mecánico con vida que turba el silencio grandioso de toda aquella inmensidad ${ }^{1}$.

\section{PRESENTACIÓN}

En los primeros días de abril de 1918, el capitán de ejército Arturo Fuentes Rabé, comisionado por el ejército chileno, inició su primer viaje a la Tierra del Fuego. En su trayecto pudo recorrer buena parte del imperio ganadero de la Sociedad Explotadora Tierra del Fuego (SETF), a la sazón soberana en la isla y en buena parte de la Patagonia meridional. De sus impresiones surgiría "Tierra del Fuego y los Canales Magallánicos” (1923), la obra etnográfica sobre la vida estanciera más detallada con la que contamos actualmente. La motivación del libro salta rápidamente a la vista: Chile se había percatado de un enorme negocio que prosperaba en los confines de su territorio, un negocio donde capital y trabajo eran indiferentes a las fronteras - geográficas y culturales- de la nación ${ }^{2}$ (chilena, pero también argentina).

Quizás sin saberlo, Rabé aterriza en un momento crucial: en la fecha de su viaje, la Patagonia es el teatro de tensiones entre estas fuerzas económicas y políticas. Asistimos con él tanto al esplendor de la crianza ovina -y al de la Explotadora en particular-, como a la víspera de las revueltas obreras que desembocarían en sangrientas represiones en ambos países. El periplo del militar pretendió entonces dar cuenta de esta patria tan ajena, registrando con

Fuentes Rabé (1923: t.II, 18).

2 Buscando verificar sus proposiciones Fuentes Rabé entrevista, cual etnógrafo, a diversos pobladores con la misma interrogante de fondo (cuál es la situación del "elemento chileno" en la región). Las respuestas apoyan sus impresiones y el tono general de su obra, como por ejemplo, cuando uno de sus informantes afirma : "La tarea más ardua que debe vencer el chileno trabajador de estas regiones, no es el clima ni el esfuerzo que demanda la rudeza de las faenas, el combate que mayor desgaste le causa, es la lucha constante que debe sostener con un elemento capitalista extraño al país $y$ con el ambiente marcadamente extranjero que rige los destinos de Magallanes.", (entrevista a Ignacio Quintana, en Fuentes Rabé, 1923: 121, t.I). meticuloso detalle las formas de organización de los establecimientos que eran allí soberanos. Fuentes Rabé se interesa por las condiciones geográficas, técnicas y sociológicas del funcionamiento de la estancia (desde la naturaleza de los emplazamientos hasta su dotación mobiliaria y ganadera pasando por la nacionalidad de sus empleados y la jerarquía laboral que los vinculaba).

En el siguiente trabajo pretendemos presentar algunas de las observaciones del militar, específicamente aquellas concernientes a la organización estanciera, complementándolas con la desclasificación de documentación inédita extraída principalmente del Archivo del Instituto de la Patagonia (A.I.P) en Punta Arenas. Se trata de copiadores de cuentas, de inventarios y de correspondencia entre las administraciones de las distintas secciones de la SETF, en un período que va de 1890 a 1920 . Intentaremos, de este modo, esbozar lo que sería una sociología histórica no sólo de la actividad productiva sino de la cotidianeidad de la estancia como institución estructurante de la socialidad patagónica de comienzos del siglo XX. Sugeriremos como hipótesis que la lógica estanciera, encarnada en la Explotadora, se revela bien distinta de los modelos sedentarios, propios a la vez de un sistema agro-ganadero como de un polígono industrial. Por el contrario, el motor tecnológico que la estructura, así como el flujo obrero que la alimenta, combinados en el repliegue estepárico, hicieron de la crianza ovina una máquina en movimiento, a medio camino entre la astucia pastoril y las prácticas post-industriales; no ya un "establecimiento", sino un enclave, un lugar de parada y de pasaje, o, como su nombre bien indica, una "estancia".

\section{LA SOCIEDAD EXPLOTADORA TIERRA DEL FUEGO ENTRE 1890 Y 1920.}

Al finalizar el siglo XIX el negocio ovejero en la Patagonia meridional y la Tierra del Fuego era ya una próspera realidad. Una primera generación de colonos, principalmente ingleses y alemanes, se había desperdigado por el territorio ocupando las mejores zonas de pastoreo a ambos lados de la frontera. Pese a no ser dueños de la tierra -el arriendo fue la forma general de tenencia-, los pioneros habían aumentado rápidamente la masa ganadera, tanto que para 1897 sólo el territorio de Magallanes contaba más de 800 mil cabezas. La 
sinergia entre migrantes, ovejas, geografía y clima daban por resultado una colonización vertiginosa, arrinconando o exterminando a los antiguos ocupantes (tehuelches y onas, principalmente).

Pero la noticia de la bonanza ovejera iba a seducir a los capitalistas metropolitanos y, tras la formación de poderosas sociedades ganaderas, los campos comenzaron a concentrarse en unos cuantos monopolios que generaron las condiciones socio-productivas ideales para el desarrollo de la actividad: un desierto demográfico interrumpido por enclaves tecnológicos con necesidad de mano de obra estacional.

La Sociedad Explotadora Tierra del Fuego fue la más importante de estas sociedades y la expresión más acabada de esta estrategia. Constituida en septiembre de 1893 a partir de la enorme concesión (1 millón de hectáreas) que el portugués José Nogueira obtuviera en 1890 del gobierno chileno en Tierra del Fuego, la Explotadora logró en menos de 20 años ocupar los mejores campos de Magallanes, Santa Cruz y Tierra del Fuego. El yerno de Nogueira, Mauricio Braun, tomó, tras la muerte de aquél, las riendas de la compañía en sus orígenes. Fue Braun quien logró el apoyo inicial de la poderosa casa comercial británica Duncan, Fox \& Co., una decisión que determinaría no sólo el destino de la SETF sino de la Patagonia entera ${ }^{3}$. En efecto, la alianza con la Duncan ofreció a Braun el sostén financiero que necesitaba para gestionar con buen margen la instalación de la que sería la más grande red ganadera en la historia de la región. Por la vía de remates, de fusiones con otras sociedades o por la compra directa ${ }^{4}$, la Explotadora puntuó la estepa patagónica con enclaves industriales (los cascos) y

3 Considerando que la Explotadora se transformaría en un imperio ganadero al sur de América, modelando no sólo la economía sino la sociedad y la política de la región durante más de 50 años, y asumiendo que es el ingreso del capital económico y social ingleses lo que determinó desde sus comienzos la organización de la compañía, creemos que el día en que Braun subió al barco Iberia, de paso en Punta Arenas, para entrevistarse con Peter McClelland, representante de la Duncan, Fox y Co. y futuro primer director de la Explotadora, fue el destino completo de la Patagonia el que dio un viraje decisivo.

4 "...la Sociedad Explotadora quedó dueña de 974.096 hectáreas (792.440 en Chile y 181.656 en Argentina), mientras arrendaba y ocupaba prácticamente 2.000.000 de hectáreas o algo más. La extensión y poderío de este imperio ganadero -el único en la historia nacional- lle- sus respectivos anexos (secciones y puestos ovejeros) a la vez autónomos y dependientes del flujo de mercaderías, de tecnología, de mano de obra, de capital, etc., que los conectaba, a través de la propia Duncan, con los mercados occidentales ${ }^{5}$. Fue en gran medida este sistema de mediaciones local-global lo que permitió a la Explotadora llevar el negocio de la crianza ovina a un extraordinario nivel de rentabilidad.

Comenzando en 1893 con la colonización de la costa occidental de la Tierra del Fuego (estancia Caleta Josefina), la compañía organizó desde entonces un complejo entramado de relaciones de producción sostenido por un poder económico hasta entonces inédito en la región. Las sumas requeridas para la puesta en marcha de tamaño negocio implicaban un seguro colchón financiero con el que avanzar sin retardo -y sin riesgos- en la constitución del latifundio. En efecto, una de las potencias de la Explotadora fue desde un comienzo su vocación expansiva: 12 años después de organizada la concesión Nogueira en Tierra del Fuego, la empresa procedió a ampliar sus territorios hacia la provincia de Última Esperanza donde adquirió en remates sucesivos los derechos de los pioneros arribados 15 años antes ${ }^{6}$ hasta ocupar el 90\% de las tierras de pastoreo. Un operación similar tuvo lugar en Santa Cruz, con arrendamientos en campos de la antigua concesión Grünbein más 180 mil hectáreas en propiedad, que formaron la inmensa estancia Fuentes del Coyle (limítrofe con la sección Cerro Castillo en Chile). A lo anterior se suma la fusión en 1906 y 1910 con las dos sociedades que representaban la competencia. Así, "a los diecisiete años de existencia, la Sociedad representaba una

gaban así al cenit en 1910. Desde las estribaciones de los Baguales por el norte hasta el lago Blanco en lo profundo del interior de la Tierra del Fuego por el sur, corriendo a lo largo de más de tres grados geográficos; y desde la base misma de la cordillera de los Andes hasta casi el Atlántico, en su parte más ancha, se extendía el impresionante dominio cubriendo tres millones de hectáreas.", (Martinic, 1992:814).

5 "Se generó así una natural incorporación a un esquema productivo imperial, en el que la Región Magallánica, junto con el resto de la Patagonia y la Tierra del Fuego, asumieron el carácter virtual de tributarias coloniales", (Martinic, 1992:797).

6 Sobre la "tragedia pionera" en Última Esperanza ver Martinic, (1985: 106-139), capítulo "El advenimiento del latifundio ganadero". 
dotación de campos dedicados a la ganadería de 2.900.000 hectáreas aproximadamente y un capital pagado de £1.500.000, aparte de las reservas acumuladas" (Durán, 1951: 43).

Esta estrategia no habría sido posible sin el favor político de las élites de ambos países que, teniendo en muchos casos intereses económicos directamente comprometidos, propiciaron una política fundiaria tendiente al monopolio. Ello pese a que el discurso gubernamental se jactaba de intenciones soberanas y civilizatorias, tales como la generación de centros poblados, cuando de hecho la región se vaciaba demográficamente (Bandieri, 2005).

Pero, más allá o más acá de su capacidad financiera para constituir la propiedad y la masa ovina, la Explotadora debía administrar eficientemente la enorme extensión que ocupaba; debía, de hecho, poner en marcha el motor ganadero. Para ello generó dos tipos de movimiento: por un lado, tecnologizó la producción introduciendo moderna maquinaria y apuntando en general hacia el automatismo de las faenas, y por otro, recurrió a mano de obra a la vez jerarquizada, calificada y estacionaria. Nos detendremos brevemente en estas dos operaciones.

\section{Las máquinas}

La Explotadora, como iremos advirtiendo, concebía su dominio como un desierto. Un desierto que, antes que civilizar, era preciso industrializar. Por esto, fue más bien la maquinización, en lugar de la población, lo que se expandió en el territorio de la empresa.

Habiendo alcanzado la industrialización británica su apogeo -así como el control político de sus colonias y su hegemonía en el tráfico marítimo-, y dado el carácter eminentemente británico de la colonización pastoril patagónica ${ }^{7}$, no es de extrañar que las últimas herramientas y técnicas aplicadas en Lancashire, Manchester o Liverpool, se expandieran rápidamente al confín del mundo.

De hecho, la vocación despobladora de la Explotadora se explica en parte por una ecuación

7 En la Patagonia chilena, hacia 1898, "los británicos que aparecen como sujetos con tenencia de campos (o de intereses en casos de compañías) poseían entonces 2.101 .390 hectáreas sobre un total de 2.930.228 hectáreas ocupadas (71,7\%)", (Martinic, 2007:77). en la cual si una de las variables era el latifundio, la otra era la tecnologización de las faenas. Esto último, que en el período pionero había quedado sólo esbozado, permitía altos niveles de producción con un mínimo de mano de obra ${ }^{8}$. Salvo en la primera -y rápida- fase de instalación, donde la construcción de los cascos estancieros (casas patronales y de obreros, galpones, corrales, talleres, etc.) requirió de un buen número de obreros, la crianza ovina se caracterizaría por su automatismo; un sueño industrial curiosamente cumplido en la "estepa". En efecto, la ganadería ovina devino un laboratorio donde las fábricas de fierro y de acero británicas, así como el know how de sus técnicos, pudieron realizar una experiencia inédita. Desde los clavos hasta los tractores, desde el alambre hasta las prensadoras de lana, desde las planchas de zinc hasta los automóviles, el "complejo estanciero" albergaba los avances recientes de la industria europea y los ponía al servicio de la producción ovejera.

La mejor referencia de esta abrupta tecnologización es la faena de esquila que, junto con el beneficio frigorífico, concentraban la mayor parte de mano de obra y maquinaria. De hecho, desde la sustitución de la tijera y del corte a campo abierto por las guías eléctricas -alimentadas a motor-en el interior del galpón, la industria no ha evolucionado mayormente ${ }^{9}$.

Aunque es preciso anotar que, tal como sucedió en Gran Bretaña en los primeros años de industrialización, ni en las instalaciones ni en la maquinaria estamos ante la iluminación ingenieril sino más bien ante un saber práctico (Hobsbawn, 1977: 54), incluso artesanal (Benavides et alter, 1996: 75), adaptado a las circunstancias patagónicas con el sólo afán de resolver problemas productivos concretos. Fuentes Rabé subraya el carácter amateur, aunque sumamente práctico de los mecánicos de la Explotadora, oficio vertebral de su organización. El militar describe a ex-marinos alemanes transformados en eficientes mecánicos a cargo de los talleres de Caleta Josefina

8 Sobre la productividad de una "estancia pionera", ver Barbería (1974).

9 Un esquilador sigue esquilando los mismos animales por día que hace cien años y las faenas duran lo mismo según la masa a esquilar y el número de hombres a cargo. Quizás la única transformación considerable ha sido el avance de la industria química con el uso de antiparasitarios de aplicación directa que han sustituido el largo y agotador baño por inmersión. 
(Fuentes Rabé, 1923: t.II, 26) o de las sorprendentes "maquinarias elaboradas por Osorio [mecánico de la estancia Springhill] [...] nacidas únicamente en su cerebro"10, mientras que en los informes de la administración central observamos la permanente circulación de otros técnicos que mantenían a punto la máquina Explotadora ${ }^{11}$.

Pese a ello, el estancamiento tecnológico desde entonces hasta la actualidad es evidente, y se debe al hecho que ni la SETF ni el resto de estancieros se interesaron en ir más allá del beneficio inmediato, esto es, la extracción y venta de materia prima sin agregar otros procesos fabriles al producto. Allí se detuvo la inversión ${ }^{12}$, ciertamente, pero allí también estuvo quizás la clave del éxito económico: altos rendimientos basados en las dimensiones de la explotación con baja inversión y baja innovación tecnológica.

Por último, a diferencia de las concentraciones urbanístico-demográficas donde este saber práctico, soporte de la tecnología estanciera, se articuló como "revolución" social, en la continuidad ovejera de las estancias, interrumpida sólo por un par de poblaciones (Punta Arenas, Rio Gallegos, Porvenir y posteriormente Puerto Natales), herramientas y técnicas se estructuraron como islas tecnológicas donde

10 "Debemos agregar que Osorio construye sus maquinarias con fierros y materiales que él mismo forja y machaca sobre el yunque, en su mayoría material abandonado", Fuentes Rabé (1923: t.II, 82).

11 En 1907 escribía A.A Cameron (Administrador General) a W. Rogers (administrador de la sección Philip Bay): "Another man has gone to put up the machinery at Ultima Esperanza, and although it will probably be advisable that Clarke goes up later on he had better remain on your Section until the machinery has been given a thorough trial, and everything is in perfect working order. I expect to be visiting Tierra del Fuego within a very short time when we can make all arrangements that may be necessary with regard to Clarkes future movements. In your letter of 30th September you say that Clarke will finish in about 14 days but I do not understand how that can be if you are still short of 40' of hydraulic pressure piping. This latter is going over now in the "Archie" there is only about exactly the quantity required. They did not send over from Useless Bay the stocks and dies necessary to screw the threads on these pipes, as I had instructed my brother, so if these are absolutely necessary you will have to send a messenger on horseback across Caleta Josefina for them..", A.I.P, fondo SETF "Copiador de Cartas SETF. Secciones Isla Tierra del Fuego, 1907-1908”.

12 "Si en el desenvolvimiento paulatino de la crianza, los productores más importantes a comprometer capitales en la etapa secundaria de transformación industrial -la lo social fue un flujo disperso que las conectaba. Es de hecho una circulación permanente de capital, de mercancías, de animales y, sobre todo, de mano de obra, lo que constituyó de manera más general la "tecnología estanciera", que en este último aspecto se aproxima, antes que a los albores del industrialismo, a formas más bien post-industriales.

\section{La fuerza de trabajo}

La Explotadora necesitaba obreros $-y$ no campesinos-calificados. La faena ovejera requería una simple aunque fina división social del trabajo -ausente en la ganadería pionera (1877-1900)- que, por otra parte, se concentraba durante la primavera y el verano -alcanzando su punto máximo en el período de esquila. Es decir, la estancia exigía una mano de obra heterogénea y especializada, al mismo tiempo que estacional ${ }^{13}$. En un principio, ante la ausencia de fuerza de trabajo y siguiendo el modelo anglosajón de crianza, se convocó en los puertos británicos -Nueva Zelandia y Australia incluidas-, a un gran número de ovejeros -con sus respectivos perros, indispensables para el trabajo- para poner en marcha los nuevos establecimientos. Con los años

instalación de plantas de beneficio y frigorización-, ello fue porque el manejo de las estancias, en la medida que se fue alcanzando la dotación conveniente en los predios, exigió el aprovechamiento económico de los excedentes anuales y, además, por la buena rentabilidad de las correspondientes operaciones, más que por un altruista propósito con fines de adelanto y desarrollo. Pero, alcanzado el objetivo, allí se detuvo la inversión y se prosiguió con la exportación de la producción, compuesta en nueve décimas partes de materias primas y en una décima de productos de origen fabril, en la forma que se había hecho tradicional, dejando a los países receptores, como eran las potencias industriales, las etapas de elaboración aún en las fases más simples, como la del lavado de lana", (Martinic, 1992:797). Este misma búsqueda de productividad la ha notado Benavides et alter. (1996:58) en sus efectos sobre la arquitectura estanciera, una búsqueda a menudo carente de cálculo industrial y a la larga anti-económica. Esto confirma a la vez cierto afán de lucro pero también el carácter artesanal de la industrialización patagónica que acabamos de indicar.

13 Asimismo vale la pena notar que, a diferencia de otros sistemas agrarios del continente (contemporáneos a la estancia), donde el trabajo era esclavo (plantaciones de caña en Cuba), pagaba un acceso a la tierra (sistema de tributos en Bolivia), o permitía la mera sobrevivencia del empleado (la hacienda en Chile) (Chonchol, 1996), los obreros patagónicos recibían un salario. 
el saber ovejero se traspasaría a obreros de otras nacionalidades -que ya desarrollaban otros oficios en la industria ovina-, sustituyendo lentamente la homogeneidad pastoral británica. No obstante, un ordenamiento raciológico-nacional, antes apenas esbozado, cristalizó en la estructura socio-productiva de la Explotadora hasta bien entrado el siglo XX: los cuadros superiores -administradores, sub-administradores, capataces- eran exclusividad de británicos, mientras que, descendiendo en la jerarquía y a medida que se diversificaban los oficios -ovejeros, mecánicos, campañistas, almaceneros, cocineros, carreros, alambradores y peones en general, más los oficios propios de la esquila- se diversificaban también las procedencias -chilenos y argentinos ocupando los puestos menos calificados y peor remunerados.

En 1918 en la estancia Springhill, por ejemplo, "el 50\% de los esquiladores son estranjeros, en su mayoria austriacos y yugoeslavos", aunque el administrador le confiesa a Fuentes Rabé estar "empeñado [...] en procurarme un porcentaje superior de chilenos, pues, he llegado a la conclusión de que este trabajador es un elemento sano de ideas y ajeno a los disturbios que ocasionan las huelgas.", (Fuentes Rabé, 1923: t2. 81). Rabé, a su vez, celebra la calidez del "elemento nacional" cuando visita el galpón, en plena faena de esquila, y los obreros chilenos -chilotes en su mayoría- lo saludan afectuosamente mientras los extranjeros permanecen concentrados en el trabajo sin distraerse un segundo. El administrador inglés afirma, por otra parte, que los chilenos son más cariñosos con el animal y que no les importa terminar esquilando menos ovejas con tal de causar el menor daño posible al animal ${ }^{14}$. Se debe anotar del mismo modo,

14 Es curioso notar como, paralelamente al interés por la importación de razas ovinas mejor adaptadas, se organizó una jerarquía racialmente marcada, expresada no sólo en el macabro exterminio ona, sino bien tardíamente con la etnicización del "elemento" chilote ("trabajador honrado aunque carente de sentido de mando" para unos, "carneros rompehuelgas" para otros). Con la instalación de la Explotadora, observamos, de hecho, el giro decisivo desde una confusión de razas, ovinas ("las ovejas traídas en el primer tiempo de las islas Malvinas eran de sangre cruzada", Yrarrázaval, 1910:18) y humanas (la "babel magallánica" de los comienzos), a una diferenciación raciológica donde un ovino Corriedale, Merino o un Romney Marsh correspondían a una clase según su resistencia, su vigor o su utilidad tanto como un inglés, un croata o un chilote. Con todo, la así como el aislamiento de las estancias, el poco contacto entre administradores y subalternos ${ }^{15}$-entre otras razones porque el inglés era la lengua franca-, delegándose en los capataces la organización in situ de la faena.

El estilo de vida victoriano de las administraciones en medio del desierto contrastaba doblemente con la ruda experiencia obrera. Por un lado, a la larga y estricta carrera que debía seguir un cadete empleado por la Explotadora hasta convertirse en administrador (Martinic, 2001: 189-193, Trincado, 2000), se oponía la vacilante trayectoria de una masa obrera en permanente incertidumbre respecto a su recontratación la temporada siguiente. En efecto, salvo la plantilla estable, esto es, administradores, contadores, capataces, ovejeros, bodeguero y cocinero - plantilla variable según el tamaño y dotación de la estancia-, el resto de empleados oscilaba al ritmo de la actividad estanciera. Por otro, si la cúpula administrativa se constituía en una vida de fidelidad a la empresa, la relación con los trabajadores -o con la mayor parte de ellos- se adecuó tempranamente a un régimen de subcontratación -tal como lo observamos hoy en día- que eximía a la Explotadora de la responsabilidad salarial, alimentaria, médica -y social en general-sobre sus empleados. La figura del Contratista asumió así, especialmente durante la temporada de esquila (aunque también en otras, como de alambrado), el rol de mediación entre el administrador y los trabajadores. Volveremos sobre esta oscilación laboral más abajo.

Con todo, en lugar de aglomerarse como desempleados en la ciudad en fechas de inactividad, muchos obreros optaban por deambular entre las

pureza de este ordenamiento zoo-humano no estuvo nunca asegurada: "De todas maneras los resultados obtenidos por los criadores son excelentes. Sin lugar a dudas, la parte científica y zootécnica de la crianza ha sido descuidada y la raza magallánica, tan deseada por algunos zootecnistas no ha sido creada, pero en cambio se ha obtenido un resultado práctico." (Calderón, 1936:15).

15 "Por parte del Administrador, no se roza con ninguno de sus subordinados y sólo hace vida social, dentro de su hogar, con los escasos visitantes extraños a su dirección. Se visita constantemente con sus congéneres de las otras estancias o sostiene con ellos prolongadas conversaciones telefónicas. El respeto hacia el Jefe es absoluto y la "Casa Grande" se mira como el albergue de un dios que rige los destinos de la estancia." (Fuentes Rabé, 1923:22). 
estancias ${ }^{16}$. Precisamente esta forma deambulatoria, que pareciera inherente a la región ${ }^{17}$ y que no sólo concernía a los obreros sino que, creemos, era un pilar en la organización de la SETF, es la que nos interesa estudiar más detenidamente a continuación.

\section{LA PRODUCCIÓN DEL DESIERTO}

En Última Esperanza vivían antes del remate [que se adjudicó la SETF] más de 600 personas, muchas con sus familias y hoy día se reduce la población en unos cuantos empleados de la Esplotadora, que van y vienen sin formar una población fija, y como la última es dueña del 95\% de los terrenos aprovechables no hay lugar para otros, ni permiten siquiera, turistas y están celosos de todo individuo que se dirije para aquella rejión aún sólo a conocer la naturaleza ${ }^{18}$.

Leyendo a Fuentes Rabé y los archivos de la SETF llama la atención cómo las estancias de la Explotadora dependían y formaban parte de una lógica, similar a la del capital hoy en día, cuya virtud consistía en mantener en circulación continua seres y objetos. Se advierte que la propiedad de la tierra interesaba menos que el control de un espacio de circulación; las enormes dimensiones de las estancias revelan antes que una ambición terrateniente, el monopolio de una red. La tierra para el estanciero, así como el mar para el marino mercante, no porta un valor en sí -de su profundidad no se extrae nada-; interesa, en cambio, como soporte o como extensión de ciertos recorridos a administrar. Ya fuera en la navegación del Estrecho o

16 Tal fue la trayectoria de James Radboune, inglés arribado a la Patagonia como ovejero en los inicios de la ganadería ovina recorriendo buena parte del territorio. Saltando de estancia en estancia, Radboune entabló también buenas relaciones con los tehuelches, la principal expresión de la itinerancia en la época, con quienes compartió largas temporadas. Su historia se puede leer en Childs (1997).

17 Baste recordar sucesivamente la itinerancia tehuelche, los trayectos costeros de los alacalufes, y luego los primeros europeos cazadores de avestruces, los balleneros o los buscadores de oro para entender que una lógica nómade, de paraderos y recorridos, de "estancias", ha delineado históricamente el territorio. La estancia, al querer homogeneizar el espacio con el flujo ovino, tuvo que combatir otros nomadismos concurrentes (ver más abajo la carta de Alejandro Menéndez) para imponer su circulación.

18 Carta de R. Stubenrauch a R. Huneeus, 5/6/1908 citado en Martinic, 1992:808. en el cruce de un guardaganado, el poder estanciero se expresaba en el control de puertas y de intersecciones, de empalmes y de bifurcaciones. En ese sentido, las toneladas de alambre que desembarcaron desde Europa para cercar los campos hablan menos de una obsesión fundiaria -delimitar claramente una propiedad- que de la regulación de estos diversos tráficos ante la amenaza de contracirculaciones o cortocircuitos: los malones onas, el cuatrerismo obrero, pero también la competencia de otras sociedades ganaderas.

El primer paso entonces en la constitución de un régimen estanciero optimizado, tal como lo preveía la Explotadora, consistió en producir el desierto, una superficie lisa en la que ovejas y ovejeros se desplazarán sin obstrucciones. La afirmación precedente de Stubenrauch es indicativa del vaciamiento de Última Esperanza y refleja el malestar de los pioneros ante el avance de este "cangrejo coloso [la Explotadora] que quiere absorber todo"19. En cuanto a Tierra del Fuego, no abundaremos aquí en las cacerías de indios, ni en la deportación de éstos a la isla Dawson, ni en el rol que cupo en ello a los misioneros, ni tampoco en la actitud de los gobiernos argentino y chileno ante la masacre a la que asistían indiferentes ${ }^{20}$. Intentaremos, en cambio, relevar brevemente dos aspectos que se articulan a esta maniobra. Pues el desierto que imaginaba la Explotadora no fue sólo demográfico sino también biológico y político.

19 Stubenrauch, op.cit. Para los pocos pobladores que permanecieron en Última Esperanza esto no fue sin angustia. Rogelio Figueroa fue uno de ellos y un permanente crítico de la Explotadora : "Es efectivo mis vacas estan mas acá de la laguna pero es por no poderlo evitar pues de mis protreros [sic] rompen ó saltan el alambrado y Ud. comprenderá no los voi a tener amarradas maxime si se trata de una insignificancia creyendo La Esplotadora no quebrará debido al pasto que comen mis animales, cuando en el campo que nosotros ocupamos en Rio Chinas pastan muchos mas y no se me ha ocurrido molestarles por esta causa. Van tres veces, sin avisarme, [que] me han llevado mis animales al corral de esa estancia lo que es simplemente un abuso...", carta a la administración de Cerro Castillo, 3/7/1911, A.I.P, fondo SETF, "Documentos varios referidos a Última Esperanza".

20 Los trabajos de Mateo Martinic (1973 y 1989) han dado buena cuenta de la "realidad" del genocidio ona a cargo de los estancieros y principalmente de la Explotadora, genocidio por mucho tiempo negado o atribuido a "las enfermedades del hombre blanco" o a una supuesta debilidad congénita. Sin embargo, con documentación aún fragmentaria, resta por conocer, entre otras cosas, los teatros de batalla, los procedimientos efectivamente empleados y la participación de otros actores sociales. 
Biológico puesto que no sólo la presencia humana, sino cualquier forma viviente que interrumpiese o amenazase los itinerarios ovinos, debía ser evacuada. Fuentes Rabé señala la amenaza que llegaron implicar unos cinco mil vacunos salvajes -baguales- que se fondeaban en la sierra Boquerón (Tierra del Fuego). Alguna vez importados para ser beneficiados, hacia 1916 se habían desperdigado sin control sobre la isla y llegaron a constituirse "en el terror de los habitantes comarcanos". La Explotadora contrató a una cuadrilla de hombres para terminar con las molestias:

En ocho meses cabales se hicieron dueños de los montes; cañadones, quebradas y cerros, fueron recorridos por la famosa cuadrilla de Azócar y González, y en todas partes dejaron huellas sangrientas del empuje exterminador que impulsaba a los jinetes. Uno a uno fueron cayendo bajo los certeros tiros, los cornudos habitantes de Boquerón.

Una vez libre el campo de aquellos molestos y peligrosos pobladores, se ha dedicado a la crianza de ganado lanar que, en piños considerables (en total unos diez mil) aprovechan, en compañía de los elegantes guanacos, el abundante y rico pasto que crece a la sombra del "leña dura" (Fuentes Rabé, 1923: t.I, 147).

La "salvajización" de animales en principio domésticos (como las vacas) fue frecuente en Patagonia. Así, una multitud de perros habría sido, tras la desaparición de sus dueños (los onas), la principal amenaza para el ganado fueguino. "Muertos o extinguidos los amos, los abandonados perros se ocultaron en las selvas de la isla y siguieron una vida mas salvaje que la que hicieron junto a sus propietarios" (Fuentes Rabé, 1923: t.II, 49) ${ }^{21}$. Ya 1896, el presidente de la SETF expresaba a M. Braun su temor:

I note that you say also about the wild dogs and the losses caused by these animals, but I hope the steps you are taking to poison them will have

21 Fuentes Rabé propone, más adelante, otro origen para los perros salvajes: "...el fundador de la estancia [Springhill], señor Jahuels, trajo del estranjero una partida de hermosos perros galgos, muy bravos y de raza rastreadora. Estos perros corrian a los indíjenas y su ocupación los convirtió en fieras tan formidables que poco tiempo mas tarde llegaron a hacerse mas temibles que la presencia de los nativos.", (t.II, 88). the desired effect, and then later on we shall be able to see if McClelland is able to get a couple of dogs of the class you want ${ }^{22}$.

Al parecer los venenos no funcionaron y los perros salvajes se multiplicaron. En 1914 la situación es crítica: durante una reunión de directorio de la SETF se discute sobre el trabajo de esa "clase especial de perros" a la que se refiere Woodsend -perros cazadores de lobos traídos especialmente desde Irlanda- que hasta entonces han matado más de 300 perros salvajes en los bosques de la isla. Y, pese a ello, continúan siendo plaga ${ }^{23}$. "Se trataba de proceder con toda energía al exterminio de estos perros salvajes", explica el Sr. Greer, administrador de la sección Cameron a Fuentes Rabé, pues "estaban causando destrozos enormes en el ganado." En un principio se previó el cercado de los bosques, no obstante, continúa Greer,

lejos de favorecer nuestros designios, se convirtió en asilo seguro para los devoradores de ganado. A raíz de tierra, los perros, hicieron grandes hoyos por los que salen a hacer sus correrías, cuando eran perseguidos huían a su escondite y el alambre formaba una barrera infranqueable entre ellos y sus perseguidores. Otras veces se convertían en admirables acróbatas y trepaban el alambrado en forma impecable. Hubo, pues, que prescindir de aquel medio y recurrir a los perros cazadores (Fuentes Rabé, 1923: t.II, 50) ${ }^{24}$.

Pero para el "monocultivo" ovino que se pretendía, el resto de vida animal también iba a constituir,

22 Carta de Th. Woodsend a M. Braun, 20/7/1896, Archivo Museo Regional de Punta Arenas (A.M.R.P.A), "Correspondencia Mauricio Braun".

23 Sesión del directorio de la SETF, 23/01/1914, A.M.R.P.A., "Correspondencia Mauricio Braun". Para dimensionar el problema, obsérvese que en 1896 Woodsend habla sólo de "a couple of dogs", es de suponer que los perros loberos importados fueron muchos más.

24 Lo notable es que estos especializados sabuesos llenaban también de "pavor al tranquilo caminante" y representaban un peligro también para los empleados. Es por ello que, en medio de estas dos furias - la humana y la canina-, ocupaban una posición liminar en la geometría estanciera: "Jamás los llevan próximo a las habitaciones; amarrados a una sólida cadena, permanecen atados en el interior de los bosques. Sólo se les da libertad cuando se les ocupa en las cacerías.", (Fuentes Rabé, 1923: t.II, 50) 
a poco andar, una perturbación ${ }^{25}$. Del lado argentino de la isla existía la misma preocupación:

...una buena batida hay que dar para concluir con los leones que quedan, y algo también hay que estudiar para esterminar los guanacos que abundan en el campo como verdadera plaga. He visto varios piños de quinientos juntos y el puestero del lote 12 me dice que él calcula que hay más de cinco mil de esos bichos. Si Vd toma en cuenta que cada guanaco come seguramente por dos ovejas podrá comprender que hay mucho pasto disponible para animales lanares [...] que aun no ha sido utilizado ${ }^{26}$.

Habría que incluir en esta lista negra a los cerdos salvajes que abundaban también en los bosques (Fuentes Rabé, 1923: t.II,49). Esta última cita forma parte de la copia de una carta que conservaba Mauricio Braun, cuñado de A. Menéndez (el autor), lo que sugiere, por otra parte, un horizonte común guiando a las sociedades ganaderas de la época. Volveremos sobre esta fuente más abajo.

Paralelo al vaciamiento biológico, era preciso además producir un vacío político, una ausencia de contrapesos administrativos que generasen las condiciones para una circulación sin trabas. Es materia conocida la débil presencia de los gobiernos chileno y argentino en los terrenos de la Explotadora -esto es, en buena parte de la Patagonia y Tierra del Fuego-, hasta bien entrado el siglo XX, y la dependencia en que se encontraron respecto de ella, sobre todo en cuanto a la vigilancia policial, a las vías de comunicación y a la asistencia médica.

Respecto a lo primero, la figura del "comisario rural", supuesto encargado de resolver litigios y velar por la seguridad local, nunca dejó de confundirse con un empleado de la Explotadora o de separarse de sus intereses (Martinic, 1985:152). En Tierra del Fuego esto fue aún más evidente, no sólo por la inoperancia estatal ante las cacerías de indios, sino durante todo el período posterior, viniendo sólo a reforzarse la seguridad policial con el inicio de la

25 "Con el desaparecimiento de los nativos, se presentó una segunda plaga constituida por los guanacos y los zorros; los primeros hacían grandes daños en los campos y los segundos ocasionaban considerables bajas en el ganado.", (Fuentes Rabé, 1923: t.II, 89).

26 Copia de la carta de Alejandro Menéndez a Francisco Campos (director-gerente de la Soc. Menéndez Behetey), 7/3/1914, A.M.R.P.A., "Correspondencia Mauricio Braun", caja 44. agitación obrera ${ }^{27}$. La jurisdicción chileno-argentina en el borderland patagónico se reducía al mínimo frente a la soberanía de la Explotadora:

El administrador y sus congéneres disponían de hecho de la autoridad sobre el extenso ámbito rural magallánico. El Gobernador del Territorio, más tarde Intendente de la Provincia, en la lejana Punta Arenas, ejercía virtualmente una autoridad nominal sobre esta vastedad territorial, únicamente a través de la policía. Pero sucede que esta se hallaba ubicada en los cascos de las grandes estancias, que les proporcionaban los edificios para sus cuarteles, los alimentos, el forraje y hasta la caballada, lo que la ponía en manos de los todopoderosos administradores, que así en la realidad pasaban a ser los señores locales (Martinic, 2001:193).

La seguridad del territorio era sinónimo de protección del desierto ovejero y la alerta se daba no ante la violación de derechos civiles, sino ante la amenaza del ganado. Es en este contexto en que comienzan a circular documentos llamando la atención sobre la presencia de intrusos, a menudo desempleados de la propia Explotadora en temporadas invernales. Notable resulta, en ese sentido, el censo que realizó en 1906 el comisario de Morro Chico H. Townsend para informar a A. Cameron -"General Manager" de la SETF- sobre la presencia de tres "freesquatters" en sus dominios ${ }^{28}$. Este tipo de merodeadores serán el objeto de permanente comunicación entre las administraciones de las secciones y de la SETF con

27 Esta dependencia era sentida tempranamente por el propio subdelegado chileno en Tierra del Fuego quien constataba que: "tanto el trabajador como los demás habitantes de Porvenir tienen que ser tributarios de las grandes estancias porque se encuentran rodeados", oficio s/n del 30/8/1898, Subdelegación de Tierra del Fuego, citado en Martinic (1973:35).

28 "Having had the occasion to take the census in my district, and remembering that you wanted a few details, re the freesquatters on your camp, I enclose you a copy of the census of each individual. You may further note that there is practically no fencing, and that the corrals, etc are very ordinary", carta del 26/7/1906, A.I.P, fondo SETF, "Documentos referidos a Zonas de Río Verde y Morro Chico". Se trata de tres personas, dos identificadas directamente ("Ernesto Casola" y "Juan Gajardo") y otra de forma indirecta ("Viuda de Jaramillo") que se han establecido "sin cercos" en 4 pequeños edificios con sus respectivos animales. Sin indicar si son familiares o no, el pequeño censo anota que en estas casas viven otras 24 personas. 
las impotentes autoridades estatales ${ }^{29}$. De este modo, la seguridad de la Explotadora en su desierto era alterada únicamente por la presencia de extraños ${ }^{30}$ o por el fantasma del ocio.

La vigilancia de este tránsito sospechoso se fundaba, en parte, en la obsesión de la Explotadora con las vías de comunicación. Los desplazamientos de Fuentes Rabé transcurren a bordo de un "excelente y fiel Ford" - a cuyas virtudes dedica floreados párrafos- y su pluma es especialmente sensible a la forma y estado de los caminos, refiriendo a cada instante la importancia de este asunto:

En un principio quedamos sorprendidos por la bondad del camino sobre el cual transitamos, sorpresa que se encarga de aclarar nuestro chofer al manifestarnos que la Sociedad Explotadora de Tierra del Fuego destina, anualmente, una suma no despreciable para el arreglo y mantención de estas vías de tránsito tan indispensables en la Isla. Un ingeniero contratado ex profeso, a cargo de una cuadrilla de trabajadores, recorre en todas direcciones las vías de comunicación dentro de los dominios de la Sociedad. Así se explica que éstas estén cuidadas en todo tiempo, haciendo extraño contraste con aquéllas cuya vigilancia y arreglo están encomendadas a las oficinas públicas.

En efecto, la pequeña periferia que constituían los terrenos fiscales y de los pequeños estancieros eran "terrenos desconocidos" donde un inspector o un militar se exponían a derroteros inciertos, entorpeciendo enormemente la labor fiscal. En cambio, en los trazados de la Explotadora la política tenía otra velocidad; ello, como puede entreverse, formaba parte de una tecnología estanciera global, donde se combinaban el interés por recorrer constantemen-

29 Al punto que, en 1911, Cameron, preocupado por la "invasión de elementos peligrosos" en los valles de Última Esperanza reclama al gobierno local, tal como Braun lo había hecho años antes respecto a los onas, "una autoridad administrativa y policial eficaz" e incluso la institución de "un juzgado inferior", carta publicada en el Diario El Comercio del 5/4/1911, citado en Martinic (1985:152-153).

30 El propio Fuentes Rabé, en su calidad de observador militar chileno, es mirado con desconfianza y con su grupo son permanentemente guiados durante sus visitas a las diversas estancias: "deseamos independizarnos un momento $y$ solos, desde una pequeña altura, observar el panorama que nos rodea. Pretextamos cualquiera cosa y logramos que nuestro guía nos dé libertad", (t.II, 46.). Esta práctica de vigilancia se repite en general con cualquier extraño. te y con facilidad sus inmensos campos y tener comunicación rápida y segura hacia las distintas estancias (los animales cambian periódicamente de ubicación) y después, la necesidad por obtener un rápido desalojo y embarque de los productos lanares que, desde la Isla, deben pasar hasta el continente $^{31}$ (Fuentes Rabé, 1923: t.II, 18).

Del mismo modo, las comunicaciones telegráficas y telefónicas tenían otro ritmo al interior del desierto de la SETF. La circulación de información era tanto o más compleja, dado el aislamiento, y tanto más crucial que los desplazamientos terrestres. De ella dependía en gran medida el automatismo que se pretendía imprimir al trabajo. En febrero de 1918 la administración de Caleta Josefina informaba "a todas las secciones" sobre la importancia de la organización eficiente de los mensajes, subrayando el valor de la sincronización en los envíos y recepciones:

In future, all communications sent from this office, via Punta delgada, to your Section, must be acknowledge together with the day and hour you receive the advice; and all communications sent from you must be confirmed by memorandum, also stating the day and hour sent ${ }^{32}$.

Fuentes Rabé observa a su vez en la estancia Cameron la función organizacional del hilo telefónico:

En un rincón, descansa el fono telefónico que une esta dependencia con la casa del Administrador. El hilo trasmisor apenas recorre setenta metros desde un edificio al otro, sin embargo funciona constantemente comunicando las órdenes impartidas por el señor Greer, que cada vez admira mas esta grandiosa invencion, destinada a mantener inviolable la disciplina (t.II, 46).

31 El funcionamiento maquínico de la Explotadora inspira profundamente a Rabé y alimenta su pluma: "Un pito, igual al de una locomotora, tocado a cierta distancia de Puerto Nuevo [Caleta Josefina], llama hacia tierra nuestra atención. Por el espléndido camino que se dirige a las casas de la estancia, avanzan enormes tractores que arrastran varios carros cargados con numerosos fardos de lana. Vistos desde lejos, semejan trenes completos corriendo por sobre terraplenes sin rieles. Todas aquellas máquinas se dirijen hácia la playa y depositan los fardos junto a la ribera.", (Fuentes Rabé, 1923: t.II, 19).

32 Circular del 5/2/1918, A.I.P, fondo SETF, "Copiador de circulares 1913-1918", folio 258. 
Por último, si los estados nacionales podían apenas interrumpir la soberanía de la Explotadora, el desamparo en que se encontraban quienes habitaban dentro de, o más bien atravesaban, sus dominios, es indicativo del vacío político que se pretendía instaurar. La organización de la producción, sus objetivos y sus medios, hemos dicho, implicaban una determinada administración de la fuerza de trabajo, aunque más precisamente de los cuerpos que la constituían. Para entender el desierto en estos cuerpos, para comprender el omnipoder que la Explotadora intentaba ejercer sobre ellos una vez incorporados a los flujos de la compañía, servirá mostrar cómo se gestionaba la salud / enfermedad de dicha fuerza. Uno de los aspectos recurrentes en la narración de Rabé es el desamparo en que se encuentran los obreros ante cualquier problema médico que los afectase. El doctor en 1918 es, de hecho, uno sólo en la isla y circula de una estancia a otra pudiendo apenas ocuparse de una mínima parte de los convalecientes ${ }^{33}$. Éstos, teniendo en cuenta la rudeza de algunas faenas, no eran pocos. De hecho, el hallazgo de una carpeta no clasificada, pero que podríamos llamar "Problemas Laborales", donde la mayor parte de los documentos refieren a accidentes de trabajo -lesionados, fracturados, amputados $e$ incluso baleados fortuitamente $e^{34}$ - nos

33 "Duro es volver a estampar esta deficiencia que se nota en todas las estancias de la Sociedad Explotadora; hemos visitado 'Caleta Josefina', 'Cameron' y 'San Sebastián', y en ninguna de ellas hemos encontrado al famoso Doctor Dao, ni siquiera un botiquín con su correspondiente practicante que sirva para atender a los necesitados. En cambio, en todas hemos visto enfermos y hemos visitado los cementerios bien tenidos, lo que prueba que únicamente se preocupan de los muertos y abandonan a los que se encuentran postrados en cama. Obra humanitaria y de sentido común, sería el que la administración general de la sociedad nombrada se preocupara de mantener en cada estancia, el personal necesario para defender las vidas de aquéllos que se sacrifican por darles las grandes ganancias y los enormes dividendos que anualmente reparte la Explotadora.", Fuentes Rabé (1923: t.II, 67).

34 "A rather serious accident happened on the 13th [marzo]. One of the men Canosa [o Canoso], cooper, was firing at some caiquenes, the bullet, which must have changed its course by striking some object, entered the back of a W.C \& struck Martinez, a butcher. The bullet has lodged somewhere in the right hip joint. Dr. France could operate, but he reckons without the $X$ rays he would have great difficulty in locating the bullet. He advises the man to be sent to P.Arenas by first opportunity.", informe del 12/3/1906, A.I.P, fondo SETF, "Correspondencia enviada de Caleta Josefina a la A. General, 1905-1906". indica el desgaste físico inherente al trabajo estanciero. Impactante resulta, por ejemplo, el agotamiento de los "matadores" en la grasería de Caleta Josefina:

Up to date over 8,000 sheep have been killed, during the past two days they have killed at the rate of 1,000 per day, as many as it is possible to boil down.

At present we have enough butchers, but after working a while they get knocked up \& almost every day there are 1 or 2 off. It would be advisable to send over 2 or 3 more if they are to be found.

The butcher who was wounded last week is doing very well, it is apparently only a flesh wound, the bone does not appear to have been injured in any way ${ }^{35}$.

El ideal de eficiencia en las faenas, el automatismo, parecía fundir el engranaje ${ }^{36}$. Pero no tendremos mayores noticias al respecto sino hasta el avance de la organización obrera que comenzó a denunciar esta precariedad. En Chile, a partir 1916, la Ley 3.170 obligaba a las empresas a indemnizar a sus empleados por accidentes o enfermedades sufridos durante la jornada laboral. De esa fecha datan también los primeros "Problemas Laborales" de nuestra carpeta. Es un indicio de que la ley, aunque débil -puesto que permitía a los patrones eximirse atribuyendo el accidente a una torpeza del empleado-, parece haber alterado la biopolítica de la SETF con una traba inesperada:

Dear Sir,

Lei 3170. Accidentes del Trabajo.

You have already had your attention drawn to the liability that now enables any employee to obtain from employer indemnity against sickness or accident. The fact that may have been inadvertently engaged whilst suffering from disease does not reduce that liability, so that if such cases should be put on the pay roll Managers render their stations liable heavy expense for sick pay, pension, etc. To avoid this, kindly note that:-

35 Informe del 20/04/1906, A.I.P, fondo SETF, "Correspondencia enviada de Caleta Josefina a la A. General, 19051906", (negritas nuestras).

36 "After working a time some of the butchers get knocked up, cut themselves \& get sick", informe del 9/03/1906, A.I.P, fondo SETF, "Correspondencia enviada de Caleta Josefina a la A. General, 1905-1906". 
in future no men are to be taken without previous medical examination by the Company's medical officer.

It being impracticable to call the Doctor to examine one or two men at odd times, we suggest you make any whom you whish to engage wait until you have others ready for examination, and with the engagement of such a group of men the doctor's visit should coincide.

We remind you that appearances form no safe guide as to a man's health. Your only reliance is upon doctor's verdict, otherwise you incur great responsibility.

We are sending you a booklet of the Law referred to when they arrive ${ }^{37}$.

Los obreros contratados, en lo sucesivo, deberán ser previamente examinados. En medio de la deficiencia sanitaria, se instala ahora la sospecha del simulacro de enfermedad. La máquina no se fía de sus desperfectos. De hecho, las "apariencias" de salud parecen sentirse como una amenaza a la Explotadora. La fuerza de trabajo ingresa en adelante a un nuevo régimen de vigilancia que en lugar de asegurar la atención médica durante las faenas se urge por prevenir el ingreso a ellas de "enfermos disfrazados" 38 .

37 A.I.P, fondo SETF, "Problemas Laborales", correspondencia del 13/9/1917 enviada desde Cerro Castillo a todas las secciones, folio 223, (negritas nuestras).

38

"Dear Sir,

LUIS SANHUEZA.

The following is an extract from letter we have written to the Manager of our Freezer, Puerto Bories:-

'... This man was examined by the doctor. You will remember he is supposed to have been hit on the head in the Sawmill [aserradero]; weather that was so or not, it is considered to be the cause of his vertigo, which according to medical opinion is nothing less than incipient insanity, and the probability of developing into lunacy within short time. Furthermore, the cross-questioning of this man made it pretty evident that he has been aware of his condition for a considerable time past.

Please be careful, therefore, not to give him employment, as if you do it will mean a heavy claim against this Company under the "Lei de Accidentes" as such men are quite sane enough to fall down whilst at work and attribute any lose of reason to such an act.'

which we pass on to you for your information and guidan$c e$, in case the above-mentioned individual should apply to you for employment.", A.I.P, fondo SETF, "Problemas Laborales", correspondencia del 1/08/1918, enviada a L. Donaldson en Caleta Josefina..
En fin, vale la pena remarcar que la producción del desierto biopolítico no fue una voluntad exclusiva de la Explotadora. Los pioneros, y luego los pequeños estancieros que resistieron en sus márgenes, buscaron también el mayor beneficio y con la menor inversión. La diferencia es que la Explotadora se acercó a este ideal que en aquéllos quedó apenas esbozado. No se trata de ciudadanos comprometidos con la región vs. compañías lucradoras -recordemos que Braun o Menéndez también fueron pioneros- sino más bien de una cuestión de olfato empresarial para saber cómo acabar con la competencia y con el resto de obstáculos (ya fueran indios, baguales u obreros enfermos) ${ }^{39}$.

\section{CIRCULACIÓN}

Una vez producido el desierto las estancias de la SETF estuvieron lejos de transformarse en establecimientos. Al contrario, el mantenimiento del régimen estepárico dependía de un tránsito continuo. En este sentido, el vaciamiento operado era antes una condición de funcionamiento que una falta de sentido progresista. La circulación animal, humana y mercantil fue la base del imperio ganadero. La inconmensurabilidad que algún momento alcanzó el dominio Explotadora era menos el de un territorio que el de una multiplicidad de redes sobre las que se montaba su negocio. Lejos estamos aquí de la idea de feudo medieval que algunos autores han propuesto (Bayer, 2002:23). La soberanía no residía en la delimitación de una comarca ni en la vigilancia de sus bordes -hemos visto la impotencia de la policía nacional-, sino en la apertura ilimitada de conexiones $y$, por ende, en el gobierno de los enlaces y de los cruces.

Rabé, al referirse a la eficiencia vial de la Explotadora, señalaba en un paréntesis (ver más

39 El mismo Stubenrauch pareciera envidiar la efectividad de la SETF. En 1904 se quejaba ante el representante del Banco de Amberes sobre su estancia Cerro Palique : "no se me ha entregado todavía dicho campo "libre de los numerosos intrusos Indios', condición que he puesto.

Estos Indios estan en el terreno con gran cantidad de animales caballares y lo peor galgos (perros) que constantemente hacen grandes estragos en la majada. El campo es inutil para mi, si no se me dé limpio de estos intrusos, y pido a Vc. Se tomen medidas inmediatas y energicas para remover dichos indios.", carta al Sr. Van Pehborg 4/6/1904, A.I.P, "Copiador de Cartas Cerro Palique 1897-1907", folio 193. 
arriba) que "los animales cambian periódicamente de ubicación". En efecto, no sólo existían campos de veraneo y de invernada donde las ovejas pastaban estacionalmente, sino que había además un tránsito desde la periferia al casco estanciero durante la esquila o los arreos para la marca de corderos. Existían también flujos ovinos entre estancias -hacia la grasería- o entre la isla y el continente -hacia el frigorífico. Tenía lugar, en fin, un tránsito constante de animales perdidos / encontrados que desbordaban los cercos divisorios de los potreros e incluso de las secciones y que constituían una masa flotante de ganado desterritorializado. Ante tamaño tráfico, y para evitar confusiones, el trabajo de marcaje corporal del ganado -cortes en las orejas para las ovejas, marcas de fuego en el lomo para caballos y vacas - tenía tanto o más importancia que los alambrados constantemente sobrepasados. No obstante, este intento de organización caligráfica también era a veces precario:

La tiza lacre que el ganado presenta en los lomos, indica a cada propietario los ovinos de su pertenencia. A causa de esta marca que es fácil de imitar, se producen innumerables desavenencias entre los estancieros colindantes y son también numerosos los altercados que estos llevan ante la justicia. Generalmente, los pequeños propietarios yugoeslavos, se proveen de la carne substraída en el cerco del vecino; este sistema poco recomendable es conocido por todos los que tienen ganado y por esta causa casi todos proceden en la misma forma. La feliz solución de tan ventajoso problema consiste en no dejarse sorprender con el delito en las manos. Cuando se suele presentar este último percance, es de ver como el substraído levanta el grito hasta los cielos, pidiendo justicia para él y castigo para el delincuente; tales clamores y aspavientos cesan en el mismo instante en que otro vecino le sorprende en idéntica tarea y a su vez lo acusa por el mismo delito para el cual el llorón pedía justicia.

Esta lucha eterna entre vecinos que se acechan y que viven sobre aviso, constituye un verdadero rompe-cabeza para el que por primera vez llega a Tierra del Fuego con la vara de la justicia (Fuentes Rabé, 1923: t.I, 143).

Lejos de asumir el carácter "yugoslavo" de estas prácticas -que Rabé pretende hacernos creer-, es posible extenderlas a una escala mayor. El tráfico, lícito o ilícito, no era sólo una cuestión de "pequeños propietarios" ${ }^{40}$ sino que incumbía también a las grandes sociedades ganaderas:

Para los estancieros de Santa Cruz no existe, por lo tanto, otra ley que la que les marca su propio interés. Conviene llevar a Chile los ganados; pues los pasan tranquilamente. Les conviene traerlos, los traen. La ley de Aduana misma parece suficientemente elástica, ya que pueden burlarla con toda comodidad. Solicitan permisos de exportación sin fijar término, y con un permiso por diez mil ovejas, por ejemplo, pasarán treinta mil, cincuenta mil o lo que quieran y en el tiempo que deseen hacerlo. Lo mismo ocurre con la importación. El pretexto de esquila o invernada permite burlar al Fisco sin pagar los derechos de aduana (Borrero, 1928: 66).

El período en que las fronteras nacionales comienzan a interferir en los dominios de la Explotadora obstruyendo la circulación animal -período al que se refiere Borrero-, refleja el valor que estos desplazamientos sin límites (territoriales) ni limitaciones (administrativas) implicaban para el funcionamiento global de la empresa. En particular, las secciones Cerro Castillo y Fuentes del Coyle, ubicadas una a cada lado de la frontera, fueron el teatro de este tipo de tráfico que en el lapso de unos años pasó de la legalidad al delito, sin que por ello dejase de practicarse $e^{41}$.

Por otra parte, los documentos de la SETF que desclasificamos aquí, documentos principalmente administrativos, describen con mayor o menor detalle -según la carpeta que se trate- el ritmo cotidiano

40 De hecho la pequeña propiedad en Patagonia se aproximaba más a los modelos clásicos de explotación ganadera, modelos pastorales antes que industriales donde la cuestión era menos la de la circulación de las majadas que del celo en su conservación, esto es, en la propiedad y sus límites. Así, sabemos por Fuentes Rabé, que muchos de estos "pequeños propietarios" trabajaban ocasionalmente para la Explotadora, entraban en su circuito, para sub-explotar después, desconectados, sus predios (1923: t.II, 25-26).

41 Una de las carpetas revisadas en el A.I.P titulada "Memorial de la SETF, 1921-22", incluye entre otros documentos una declaración de altos cargos de la SETF que confirma este interés en traficar libre de impuestos animales entre Chile y Argentina, principalmente en temporada de esquila, así como un juicio por este mismo caso que, entre otras consecuencias, dejaba sin trabajo a los esquiladores de Fuentes del Coyle. 
de los circuitos de la compañía. Como hemos visto, figuran en ellos asuntos relativos al tráfico marítimo y terrestre, al abastecimiento de mercaderías, al enganche de mano de obra y a la organización global del trabajo. De entre ellos llama en particular la atención el "Copiador de Circulares" redactado por el General Manager para instruir o informar permanentemente a todas las secciones. El título del volumen denota perfectamente la función que dicha correspondencia tenía en cuanto a la aplicación de los mismos procedimientos productivos en todas las estancias ${ }^{42}$. El siguiente extracto, que nos permitimos transcribir in extenso, es representativo de esta relación entre circulación de información y automatismo productivo:

\section{W.R. Cameron Esq:}

Caleta Josefina

CIRCULAR LETTER addressed to the Managers of the different sections of the Sociedad Explotadora de Tierra del Fuego on the subject of LAMB-MARKING.

In view of the approach of the lamb-marking Season I take this opportunity of calling the attention of the Managers to the very great importance of this operation and to the necessity of giving it their special attention in order that the work may be carried out in the best possible manner.

There is no gain in breeding a large number of lambs, and then for the lack of a little care and forethought allow a large proportion of them to be mis-mothered and lost at the marking a month or two after there were born. Any extra care and expenses given to the operation will be always well repaid.

The following are some of the essential points to be taken into account during the operation of lamb-marking:-

1. To have sufficient number of corrals in suitable positions in each camp in order to avoid the driving of the sheep a long distance to the corral.

42 Se trata de 274 folios, fechados entre 1913 y 1918 , muchos de los cuales vienen en varias copias para las distintas secciones y a menudo en español e inglés. Abunda el envío o recepción de "formularios" (forms) que debían ser rellenados por los administradores de cada sección, habiendo un formulario específico para una diversidad de operaciones.
In the course of a long drive some of the lambs are sure to get mis-mothered before they reach the pens, in which case the mothers are likely to rush off as soon as they let go to the spot they were first missed their lambs, instead of looking around the corrals for them, as they would do if they only lost them on arriving close to pens.

2. The advantage of a sufficiency of pens also enables the sheep to be brought into the corrals in small points,--the smaller the better,- as if the sheep are brought in large numbers the ewes get so hungry and thirsty before finally being released that they only think of satisfying these desires before looking for their lambs.

3. The Ewes should be brought together in small flocks and released as soon as possible.

4. Sheep should never, unless under very exceptional circumstances, be brought into the corrals overnight, for the reasons given above.

5. The ordinary mothering pen is generally useless for the purpose for which it is intended. The 'mothering' can be much better done out in the camp, an a couple of the most trustworthy men should be told off for this duty and follow every gang for this express purpose, keeping the flock carefully and well in hand till they are satisfied that the mothering has been well accomplished.

6. As a rule the lamb marking is hurried over far too quickly. Any efforts breaking must be STRONGLY REPRESSED, and in the event of rough weather coming during the operations, when, the work should be delayed until favourable conditions obtain. It is only natural that the lambs are to quickly find their mothers during calm mild weather than during gales of wind and dust $^{43}$.

En este circuito disciplinario de la información, es posible apreciar también las otras dimensiones de la estancia en que los elementos debían circular. Un espacio problemático donde esto se materializaba

43 Circular del 1/10/1913, A.I.P, fondo SETF, "Copiador de circulares 1913-1918", folios 20-21, Sobre el automatismo, Rabé refiere una y otra vez la escrupulosa coordinación de las faenas que, ciertamente de forma aún artesanal respecto al maquinismo contemporáneo, regía sin embargo desde el primer al último movimiento: "A las cinco de la mañana todo es actividad y vida. Una enorme campana deja oir su metálica voz e invita a los operarios para que den comienzo a las labores diarias.", (1923: t.II, 20). 
era el intercambio en el almacén o despacho. Cada estancia poseía uno de estos comercios, que la Explotadora aprovechaba, como un circuito cerrado, de forma que ningún tráfico escapara a su dominio. Así, la compañía adquiría en Europa y EE.UU mercaderías diversas -desde vestimenta hasta abarrotes, medicinas e incluso armas- la mayoría ajenas a los mercados chileno y argentino, y que ofrecía en exclusiva a sus obreros. Se trataba de un lugar problemático puesto que los trabajadores no tenían más opción -el siguiente almacén era la ciudad-que comprar todo aquello que no les proporcionaba la Explotadora a la propia empresa, abriendo cuentas que luego se descontaban de sus salarios. El conflicto surgía entonces en la medida en que

...los precios se mantienen siguiendo las fluctuaciones del cambio internacional; la reducción de chelines y peniques a moneda chilena, confunde $y$ desconcierta a los consumidores. Y como éstos sólo perciben sus salarios al final de las faenas, hacen sus pedidos por medio de vales que se van acumulando hasta el arqueo total. En esta época estalla la protesta general, protesta que se evapora en medio de chelines, peniques y libras esterlinas reducidas al insignificante valor del papel moneda (Fuentes Rabé, 1923: t.II, 26-27) ${ }^{44}$.

Los libros de contabilidad a los que hemos tenido acceso detallan el seguimiento acucioso de los haberes y deudas de cada obrero. Fuentes Rabé, esmerado en su trabajo etnográfico, alcanza a realizar algunos cálculos a espaldas de sus anfitriones:

Hemos recogido algunos datos que se refieren a las ganancias obtenidas por estos "despachos" durante el primer semestre del año en curso (1918) y ellos revelan que estos almacenes, instalados para proporcionar los artículos a precio de costo, están muy lejos de reflejar tal propósito. Las ganancias suman buen capital y parece que una parte bien apreciable de los sueldos acumulados por el trabajador, vuelve a las cajas de la estancia (t.II, 27).

Pero el control de la circulación animal y mercantil es el correlato del principal de los flujos, o

44 Este círculo "virtuoso" era percibido también por los obreros: "...esos almacenes no son para atender a las necesidades de los trabajadores creadas por la industria sino para lucrar a costa de éstos.", (Iriarte, 1915: 37). al menos del que más nos interesa aquí: el humano. Hemos referido fugazmente más arriba el carácter inestable de la mano de obra encarnado en la figura del Contratista que hacia 1915 se había constituido en el mediador de la relación entre la Explotadora y la mayor parte de la mano de obra, esto es, los obreros estacionales. La subcontratación, en efecto, permitió a la Explotadora realizar una economía casi perfecta de medios de producción y fuerza de trabajo.

Este cálculo se empleaba ya en las primeras etapas de su organización: se trataba de mantener un celoso equilibrio entre empleo y desempleo, según las temporadas de mayor o menor actividad. Al acercarse el otoño de 1906 -período de escasez de mano de obra-, T.G Cameron, administrador de la estancia Caleta Josefina, escribía a su hermano Alejandro, administrador general en Punta Arenas:

Work started at the Graseria on the 5 th. We are very short of hands_only 5 peones turned up_ one of these was the mozo, whom have had engaged at $\$ 40$ per month. I enclose herewith a list of peones \& carniceros, passengers per 'Araucania'. If it is possible to get a few more peones it would be advisable, I have had to pay all the peones $\$ 90$ per month, \& some $\$ 100$ the men on the night shift \& others doing heavy work. Considering we pay such a high wage, it is necessary to put through the greatest possible number of sheep per day, \& get the business finished sooner ${ }^{45}$.

Una situación radicalmente opuesta ocurría en la primavera -época de abundancia de mano de obra- del año siguiente, cuando ahora A. Cameron informaba al administrador de la sección Springhill:

Men are plentiful here just now so there will be no occasion to raise wages at any rate for some

45 Correspondencia del 9/03/1906, A.I.P, fondo SETF, "Correspondencia desde Estancia Caleta Josefina a la Administración General”, años 1905-1906. Algo similar ocurría con los ovejeros: "We are getting rather short of shepherds. If there are any to be had in P. Arenas we could do with 2 or 3. Two of our men are going home, \& two more who left for a short holiday recently, have found work elsewhere, at a higher wage", correspondencia del 12/03/1906, A.I.P, fondo SETF, "Correspondencia desde Estancia Caleta Josefina a la Administración General, años 1905-1906". 
considerable time and unless the mines occupy a great number of men we shall be able to keep the price of labour down to a reasonable limit... ${ }^{46}$

Así, para conservar los sueldos en un "límite razonable", los trabajadores no debían partir -pues en tal caso la escasez de mano de obra obligaría a subirlos- sino permanecer, circular, a un cierto radio de la estancia, disponibles para cuando se los requiriese. En caso de disidencia, de abandono de los circuitos de la Explotadora, era preciso asegurarse de haber extraído del "elemento" el máximo rendimiento posible. El General Manager Cameron se lo explicaba en 1907 al administrador de la sección Philip Bay a través del caso de unos ovejeros escoceses:

Contract shepherds: In reference to your query inletter $N^{\circ} 117$ re the four shepherds named:

Rose
Bain
Harper H.
Harper D.

Sent from Punta Espora, these men have to be debited with

$£ 17$ passage from Scotland to Punta Espora

\section{$£ 1$ cash in Punta Arenas \\ $\underline{£ 18}$ total}

to the debit of each one. You should have received advice of this from Springhill, as they were advised of these advances when the men sent down to Punta Espora. You must endeavour to utilize these men profitably until they paid the amount of their passages at all events ${ }^{47}$.

De ahí que la Explotadora, pese a reconocer en el desempleo un problema -como veremos detalladamente en la última parte de este trabajo-,

46 Correspondencia del 7/09/1907, A.I.P, fondo SETF, "Copiador de Cartas SETF. Secciones Isla Tierra del Fuego, 1907-1908",

47 Correspondencia del 14/10/1907, A.I.P, fondo SETF, "Copiador de Cartas SETF. Secciones Isla Tierra del Fuego, 1907-1908" (negritas nuestras). una contra-circulación que amenazaba el régimen en su conjunto, concluía que el vagabundeo era funcional a la máquina aunque urgía regularlo. Así lo resolvió el administrador Greer $^{48}$, de la estancia Cameron, ante el caso extremo de un individuo que rechazaba el trabajo:

.. logramos ver al indio Santiago; vive en las inmediaciones de la Estancia, viste a la moderna, no trabaja en nada y diariamente acude a la casa principal en demanda de alimentos. La Compañía lo retiene en su poder $y$, mensualmente, lo gratifica con una libra esterlina a fin de que pueda invertirla en el almacén de Cameron. Lo mantiene y lo viste a condición de que no robe ganado y de que no tenga perros salvajes (Fuentes Rabé, 1923: t.II, 51).

Esta suerte de "raciones" ofrecidas por Greer-que evocan las que ofrecían los gobiernos argentino y chileno a los mapuche a cambio de la paz-, son el negativo -para el desempleo- de lo que vino a ser la subcontratación -para el empleo. En este sentido, la subcontratación abrió aún más el campo de la circulación obrera. A través del contratista se ampliaban las redes de reclutamiento de la fuerza de trabajo al tiempo que se reducían los trámites para su posterior liberación. Por otra parte, negociando sólo con el contratista, la Explotadora se ahorraba no sólo la operación de "enganche" sino también el hecho de dirimir

48 Raciones que continuaron ofreciéndose años más tarde. En 1954 uno de los cadetes de la Explotadora, Roberto Trincado, encontraba a uno de estos merodeadores, el fugitivo Olave, en la sierra Dorotea (Última Esperanza): "Observé el pobrísimo lugar y vi que había unas doce piernas y paletas saladas de ovejas ahumándose, colgadas del techo. 'veo que está bien aperado para el invierno', dije, creyendo ser divertido. 'Hay que estar pues; tengo una familia ¿ve?', dijo mostrando sus perros. 'Y que le hace a la explotadora pues, si es como sacarle un pelo a un buey, ¿no?'. 'Es que las ovejas que hay cerca de la estancia son finas don Olave', le comenté, exprimiendo mi cerebro.

'Hey sí que me embromó pues', dijo. 'Aura sí que'stoy fregao no más'. Y quedó muy preocupado. Sonó sobre las tablas una granizada, y me levanté para irme: 'Pero todo tiene solución pues, don Olave; cuando usted necesite carne o algunos víveres, venga a la estancia y nosotros le daremos lo que podamos”. '¿Y sobre los Carabineros?'. 'No se preocupe pues; por mí naiden sabrá que usted anda por aquí', le dije en su propio lenguaje.", (Trincado, 200:65, negritas nuestras). 
en los numerosos conflictos que hacia 1920 se fueron produciendo ${ }^{49}$ :

Como los contratistas asumen directamente toda responsabilidad corriendo con la direccion de los trabajos, pago de los obreros, alojamiento, mantencion y atencion de la jente contratada; viene a ser un intermediario responsable entre la Administracion y el trabajador. Tal ocupacion, llena de sinsabores y asperezas, deja pingües ganancias al contratista, ganancias que se derivan del trabajo en las mismas faenas ya sea de economias en las raciones (que siempre son muy abundantes) o de mayor precio por animal esquilado.

Este último punto es de necesidad apreciarlo, pues las administraciones a fin de verse libres de tratar directamente con el esquilador, asignan a éstos una cantidad determinada, jeneralmente 26 centavos por animal esquilado, dejando al contratista, por el mismo animal la suma de treinta o mas centavos (Fuentes Rabé, 1923: t.II, 100).

El "contrato" era la herramienta en que se plasmaba esta sujección diferida en que entraban los obreros al incorporarse a alguna de las estancias de la compañía. Pese a la liberación de responsabilidades que garantizaba por esta mediación la Explotadora, era preciso asegurar que dicho liberalismo no desbordara ni obstruyera la red una vez "enganchados" los nuevos empleados:

To the Managers, ALL STATIONS.

\section{Dear Sirs}

The following is a transcript of contract signed by the men who have just arrived from the North per s.s "CHILOÉ":

\section{CONTRATO DE ENGANCHE}

“... En Castro á Dieciocho dias del mes de Diciembre de mil novecientos dieciseis los abajo

49 "Las distintas administraciones sólo supervijilan este trabajo y nada tienen que hacer con los esquiladores, es decir, la Jerencia entrega las faenas al contratista y se desliga en absoluto de toda cuestion que se relacione con las diverjencias que puedan presentarse entre el concesionario y los trabajadores que este haya contratado.", (Fuentes Rabé, 1923: t.II, 23). suscritos han celebrado el siguiente contrato con los Señores Braun y Blanchard, representantes de la Sociedad Explotadora de Tierra del Fuego, en Magallanes, para prestar sus servicios en las Estancias de la referida Sociedad:

$1^{\circ}$. Nos comprometemos á prestar nuestros servicios en cualquiera faena que se nos designe en las Estancias de la referida sociedad.

$2^{\circ}$. Declaramos por el presente contrato que estamos desligados completamente de la $\mathrm{Fe}$ deración Obrera de Magallanes mientras estemos con este compromiso, y que cumpliremos con exactitud nuestros contratos para trabajos en las Estancias citadas.

$3^{\circ}$. Quedamos conforme con el sueldo mensual asignado de 26.10 o Seis libras esterlinas y diez chelines que se nos abonará desde el Jueves 21 del presente mes y ademas la comida diaria desde el dia del embarque.

$4^{\circ}$. Se declara que la Compañía se obliga á proporcionarnos el pasaje de aquí á Punta Arenas y hasta las Estancias y el de regreso del mismo punto á Castro una vez que no sean necesarios nuestros servicios.-

which we pass on to you for your information.

We are, dear sirs,

Yours faithfully,

Por La SOCIEDAD EXPLOTADORA DE TIERRA DEL FUEGO,

\author{
T.R.D Burbury \\ General Manager ${ }^{50}$
}

El detalle de la interdicción de cualquier tipo de vínculo con la Federación Obrera de Magallanes es un indicio de la principal traba que entorpeció la organización soberana de la Explotadora en el período que nos ocupamos. En efecto, la actividad sindical, desde principios del siglo XX, fue creciendo como un excedente, o un síntoma, indisociable de la economía practicada por la compañía, esto es, de la múltiples circulaciones -entre ellas la obrera-que su biopolítica propiciaba. Se trató, de hecho, de un cortocircuito

50 Circular del 28/12/1916, A.I.P, fondo SETF, "Copiador de circulares 1913-1918", folio 159. 
que afectó sensiblemente las distintas secciones del imperio ganadero, una avería que señaló el ejercicio de otros itinerarios, la existencia de otras encrucijadas y de otros enlaces en el desierto estanciero.

\section{CONTRA-CIRCULACIONES}

Snow fell again here a couple of days ago to a depth of three or four inches. I should glad to see the spring again. I have never seen the camps here so full of loafers as this year, bad characters most of them ${ }^{51}$.

La referencia al vagabundaje aparece ya en la literatura patagónica de fines del XIX (Spears, 1895; Eyzaguirre, 1897; Payró, 1898) ${ }^{52}$. Abordado desde diferentes perspectivas, aunque subrayando en general la astucia y la capacidad de supervivencia del obrero errante, es en la crónica de Spears donde éste aparece como un personaje en el paisaje local, desde los comienzos, e incluso antes, del imperio ganadero. Spears dedica un capítulo completo a los "Patagonia's Tramps" de la época con los que se topa una y otra vez durante su viaje:

It is common for people of New York who have accumulated enough money to enable them to retire from business to speak of themselves as "living in independent circumstances." They can live without work. These tramps are also in independent circumstances. They can live without work. It was written, that if a man will not work neither shall he eat. We now find ourselves obliged to modify the old-time interpretation of this scripture. I do not pretend to offer any suggestion in the matter of relieving the toilers from the incubus of the loafers but those who are engaged in solving the problem, ought to know and to consider the fact that in desert Patagonia the number of tramps is greater in proportion to the population than it is in the well-settled parts of the United States (Spears, 1895: 259)

51 Carta privada de T.R.D Burbury a A.Cameron de 30/08/1908, A.I.P, fondo SETF, "Correspondencia Sección (Estancia) Cerro Castillo con Administración General en Punta Arenas, años 1906-08-09-11".

52 Se trata de cuatro periodistas (los dos primeros norteamericanos, los dos segundos argentinos) que visitaron la región en la década de 1890 y cuyas crónicas vinieron a abrir el campo narrativo sobre la región hasta entonces colonizado por el relato científico-militar.
Esta proporción parece haber ido en aumento. En efecto, hacia el final del primer decenio del siglo XX, al extender progresivamente su masa ganadera así como las dimensiones del latifundio, la Explotadora había aumentado también el trabajo estacional concentrado principalmente en las faenas de esquila, frigorífico y grasería. Es sabido que la mano de obra estanciera se constituyó principalmente de población migrante ${ }^{53}$. Pero, a diferencia de lo que sucedió y sucede en otras latitudes, en la estepa patagónica la migración no tenía ciclos: en particular para los europeos, aunque entre los nacionales lo fue progresivamente, el final de la temporada no marcaba el retorno a casa. El migrante devenía así nómade ${ }^{54}$.

Al ritmo autómata que imprimía la Explotadora a sus operaciones, se oponía, en principio, la imprecisión de un creciente vagabundeo proletario. Éste, desconectado de la red productiva, constituía una obstrucción de la que, al igual que los animales salvajes, era preciso deshacerse o, al menos, controlar, cercar. Así lo entendía Alejandro Menéndez en un párrafo que antecede al ya citado sobre el exterminio de los baguales:

Los carreros son gente de la peor especie, roban animales cuando necesitan carne, rompen lo que encuentran por delante y que pueda ser un obstáculo á la facilidad de su transporte, pastorean sus animales por el tiempo que les place y donde les place. En una palabra son verdaderos vándalos destructores [...] Los arreos de ovejas que cruzan los campos son numerosos y los arreadores son menos civilizados que los carreros, por no decir mas ladrones. Llevan por delante lo que encuentran. No hay respeto por la propiedad agena. Y si todavía se agrega que mezclan sus animales sarnosos con los de la Sociedad puede facilmente

53 La incorporación de indígenas a las faenas estancieras fue rara. Durante todo su trayecto, Fuentes Rabé señala la presencia de un sólo empleado indígena que, aún atormentado por el recuerdo del genocidio, trabaja no obstante para la Explotadora. En los libros de cuentas revisados descubrimos junto al listado de asalariados tan sólo dos paréntesis excedentarios que agregan al apellido la clasificación (indio).

54 "El nómade no es en absoluto el migrante; pues el migrante va en general de un punto a otro, incluso si este otro es incierto, imprevisto o mal localizado. Pero el nómade no va de un punto a otro más que por consecuencia y necesidad de hecho: en principio, los puntos son para él empalmes en un trayecto.", Deleuze y Guattari (1980: 472) 
comprenderse la importancia inmensa de poner un remedio á tanto mal. No hay más que uno á mi juicio, que es al mismo tiempo el más seguro y el mas económico: alambrar los caminos públicos. [...] Poco a poco se irán acostumbrando á la nueva situación y respetarán los cuadros particulares.

Para el interés latifundista se trataba, en definitiva, de una cuestión de velocidades. El tráfico subversivo, así como los contagios peligrosos, podían administrarse acelerando la propia red de comunicaciones, suprimiendo de esta forma los derroteros inciertos:

En el Oriental [estancia propiedad de la Sociedad Menéndez Behety] donde la estensión es tan inmensa un aviso de importancia no llegará á tiempo. Tal vez el ovejero por no incomodarse dejará robar un capón y se ahorrará así un galope de varias horas.

¡Cuantos beneficios nos reportó á nosotros el teléfono á Tierra del Fuego cuando se daba gran vuelo á los trabajos de aquellos establecimientos y teníamos que librarnos de los malones de los indios onas. Aquí son los indios blancos que hay que sorprender y castigar y nada facilitará más esta tarea que una buena línea telefónica. Tambien se evitará mucho movimiento de peones y caballos con dicha instalación y con mejor servicio se podrá mejorar el personal ${ }^{55}$.

El devenir salvaje de estos obreros-pasajeros, los "indios blancos", constituía una especie de atavismo nómade que inquietaba a los administradores ${ }^{56}$. Se trataba de trayectorias que desconocían, y en

55 Copia de la carta a Francisco Campos, op. cit., (negrita nuestra).

56 Notable resultan al respecto las divagaciones de "el Jimmy" sobre su acostumbramiento a la vida tehuelche. Pese a disfrutarla, temía convertirse en salvaje: "Jimmy había disfrutado tanto su vida en los toldos [...] que creyó mejor no regresar con ellos al río Zurdo al término de la estación de guanaqueo [...] tenía a Harries y sus descuidadas maneras como ejemplo de un inglés a quien le habían llegado a gustar demasiado los indios." (Childs, 1997:118). Y más adelante se insiste en que el problema "era su conciencia inglesa. Mientras se deleitaba con su libre vida, su conciencia lo aguijoneaba. No veía por qué no podía seguir viviendo como lo hacía, pero estaba continuamente obsesionado por el sentimiento que debería dejar esa vida, conseguirse una tierra propia y desarrollar una estancia u obtener un trabajo que lo llevara a algo.", (op.cit, 171). cierto modo profitaban, del desierto ganadero, cuyo vacío político (ausencia de jurisdicciones nacionales) permitía desplazamientos sin norma. Pero, al mismo tiempo, esta fuerza de trabajo flotante, "ejército de reserva", constituía un pilar fundamental de la economía política de la Explotadora. Se instalaba pues, para la empresa, una disyuntiva cuyo cálculo y solución transcribe Fuentes Rabé:

Referente al movimiento de trabajadores, hay algo curioso que observar; especialmente durante el invierno, época que obliga a paralizar toda faena en la Isla, sólo permanece en las estancias el personal necesario para el cuidado del ganado y los distintos talleres que continúan funcionando. No obstante, esta reducción en el número de operarios y a pesar del intenso frío que se descarga en la región, los establecimientos se ven visitados continuamente por cantidad considerable de trabajadores que se presentan pidiendo alimentación y alojamiento.

Es incomprensible -dice el Sr. Donaldson [administrador de Caleta Josefina]-, cómo esta especie de trabajador nómade tiene energía suficiente que le permita cruzar la Isla desde un extremo a otro y en todas direcciones, sin más abrigo que el indispensable para cubrir su cuerpo y sin mayor alimento que aquél que le proporciona el ganado de los caminos.

El terreno que permanece cubierto por una extensa y gruesa capa de nieve, no es obstáculo suficiente para que estas cuadrillas ambulantes puedan pernoctar en medio de la soledad y rodeados por la oscuridad más completa.

Bien conoce el obrero fueguino que en la época del invierno, es tarea inútil llegar hasta las estancias en demanda de trabajo; sin embargo, todos los años, después de las faenas, permanece en Tierra del Fuego, un número considerable de desocupados que opta por llevar una vida nómade y llena de sacrificios en lugar de trasladarse a lugares habitados en demanda de un descanso que bien se merece.

Este grupo de hombres desocupados, se divide en distintas partidas que se lanzan a través de los campos con la intención preconcebida de vivir de la comarca. Por esta causa, cada estancia recibe, más o menos, en la misma época, un número crecido de albergados. Generalmente se les señala un plazo para que puedan abandonar el establecimiento, determinación que de nada sirve toda 
vez que las cuadrillas, obrando de acuerdo, dejan expedito un local para que sea inmediatamente ocupado por un número, más o menos igual, de la misma partida. En esta forma, pasan el invierno completo y sólo abandonan una estancia cuando un grupo igual de compañeros deja la vacante en otro establecimiento.

Y lo peor del caso es que no se les puede negar hospedaje y resulta más económico recibirlos que rechazarlos. Al quedar desamparados en los campos, obran con maldad y, a manera de venganza concluyen con piños completos, abandonando las reses muertas en medio de los caminos.

Esta vida errante y sin comodidades de ninguna especie concluye con muchas vidas proletarias y es la causante de daños enormes en el ganado lanar (1923: t.II, 30-31, negritas nuestras).

Al igual que con el indio Santiago o con el fugitivo Olave, el administrador de Caleta Josefina concluye que más vale "recibirlos que rechazarlos". Lo que parece, según Menéndez, una verdadera amenaza para la continuidad ovejera, termina por asumirse como un costo inherente al sistema que se pretende implantar. La Explotadora sabía que la vía policial era mucho más estrecha que "sus vías" y, por ende, había que, como en el caso de los freesquatters de Morro Chico, vigilar y, llegado el caso -como propone Menéndez-, castigar. Pero ni el censo ni las "raciones" alcanzaban a disolver estos contra-circuitos que ganaban en intensidad a medida que afluía y afluía la mano de obra ${ }^{57}$.

La complejidad metodológica de rastrear este movimiento ambulatorio es evidente. No obstante, referencias al nomadismo obrero aparecen interrumpida aunque frecuentemente en los documentos consultados y en la literatura disponible. De entre ellas, hay dos puntos o posiciones recurrentes. Dos puntos en los que el tráfico subalterno parece confluir; dos posiciones que, en la topología es-

57 "Sucedió así que, pasado 1910, se produjo una sobreabundancia de mano de obra que no estuvo en situación de ser absorbida por una economía que, aunque fuerte, había completado su estructuración y sólo requería de nuevos contingentes en grado limitado.[...]

Las consecuencias directas e inmediatas de la saturación ocupacional, relacionado con la afluencia inmigratoria, fueron por una parte la cesantía de trabajadores y la reemigración hacia otras regiones, en particular hacia el territorio argentino de Santa Cruz.", (Martinic, 1992:906). tanciera, marcan una línea de fuga respecto a los cascos administrativos. Hablamos del "puesto" y del "boliche".

El puesto ovejero, pequeña y precaria habitación donde uno - $\mathrm{O}$ a veces dos- ovejeros se instalaban en general durante el invierno para cuidar el ganado, se caracterizaba por su excentricidad ${ }^{58}$. Como lo señala Menéndez, para el "puestero" implicaba un "galope de varias horas" desplazarse hasta el centro estanciero. Este estado de "desolación"59 favorecía su carácter de albergue para el proletariado flotante y alimentaba los más diversos temores. T.R.D Burbury, administrador de Cerro Castillo y sucesor de Cameron en la administración general, escribía al respecto al aproximarse el invierno de 1908:

I am very much troubled this winter by the presence of unemployed men in the monte many of whom are bad characters. In the rincon of the Rio Baguales where Braun \& Blanchard maintain a Campanista named [¿Pedro?] Juan Díaz looking after a few mares (I understand their property) a whole gang of horse thieves was in their puesto. This

58 Esta excentricidad era, en ocasiones, también propia de los puesteros: "-Contratamos -nos dijo [el administrador de Cameron]- dos ovejeros escoceses, solteros, y se los instaló en el puesto que Uds. pudieron observar junto al mar y algo apartado de Cameron. Allí permanecieron por espacio de dos meses entregados a su trabajo [...] ambos trabajadores llevaron una vida en común, pero jamás se dirigieron la palabra. Un día, al final del segundo mes, el más joven, recorriendo el campo encontró entre las arenas de un río, una bonita pepa de oro. [...] Con su valiosa pepita corrió al puesto donde se encontraba su compañero, con la intención de participarle la feliz nueva. Más rápido que de costumbre, empujó la puerta de la habitación y, a boca de jarro, lanzó los: "ibuenos días!". No alcanzó a decir más. Era la primera frase que se cruzaba entre estos dos europeos. Esta sola frase bastó para que el más viejo de los escoceses, sin despegar los labios, se levantara y ensillara su cabalgadura. Dos horas más tarde se presentaba ante mí reclamando de la charla loca de su compañero. Tuve, pues, que ajustar las cuentas a los dos amigos del silencio, los que, sin agregar palabra, se marcharon mudos en demanda de otra estancia que pudiera proporcionarles trabajo, asignándoles a cada uno un puesto solitario en medio de la selva.", (Fuentes Rabé, 1923: t.II, 52).

59 "Triste, en verdad, es aquel lugar [el puesto] de destierro para los infelices que deben habitarlo. Solos en medio de la inmensidad espantosa de aquellos lugares solitarios, el alejamiento absoluto de centros poblados, y más que nada, la época de frío intenso para la cual está destinada, hace que se mire aquel punto, como un lugar de expiación para los desheredados de la fortuna." (Fuentes Rabé, 1923: t.II, 41). 
question of that 'rincon' is always a recurring one and the entire use of that ground is denied [to] this farm because the puesto is private property and a man is maintained in it who has continually crowd of loafers lodging with him, running [ibounds?], finding stay at houses amongst the sheep etc.

Estas intrusiones ameritaban el recurso a la policía que, como de costumbre, era dirigida y abastecida por la propia compañía:

In [¿Wohlees?] old house near Rio Vizcachas I put the Argentine Comisario and his three men. I make the arrangement with Sr. M. Caudioti, the Governor of the Territorio of Santa Cruz, to supply them with meet, house and fuel [...] The squad sent are certainly a good one \& have been most useful to me in charring out Cazador monte of loafers.

Sin embargo, concluye Burbury, la aglomeración en el puesto tenía otro punto de referencia:

In Tapi-aike there are yet no less than three bôliches [sic] close to $v$. Heinz and opposite Guillermo Schelkley's house. These men also encourage the congregation of loafers and must annoy $v$. Heinz pretty considerably. He suggested me asking the Comisario to shift them but I doubt intend to pull von Heinz's chestnuts out of the fire ${ }^{60}$.

El boliche, a la vez almacén, bar, casa de juegos y hasta prostíbulo, fue figura repetida en las crónicas de la época. Pero, mientras que en la ciudad el boliche aparecía como el lugar de esparcimiento por excelencia ${ }^{61}$, en la estepa se trataba también de un sitio de refugio y abrigo. No obstante, en ambos espacios se producía "un intercambio de información, de datos sobre nuevos trabajos o simples chismes del barrio, en un diálogo facilitado por la relación cercana, cuando no íntima, entre el bolichero y su clientela" (Díaz, 1994:112). Con todo, mientras en la ciudad el problema, deplorado permanentemente por la prensa, era el alcoholismo, el boliche estepario era además objeto de otras sospechas. Para los estancieros no se trataba sólo de un "nido de

60 Carta a A. Cameron de 31/05/1908, A.I.P, fondo SETF, "Correspondencia Sección (Estancia) Cerro Castillo con Administración General en Punta Arenas, años 1906-0809-11".

61 En Punta Arenas, a fines del XIX, se calculaba un boliche por cada 25 habitantes (De Agostini en Diaz, 1994: 109). cuatreros" o de un enclave donde los alambrados se confundían $^{62}$; hacia 1920 también era el albergue de la conspiración:

Al llegar 1921 Deseado y Gallegos se encuentran en huelga general y el boicot afecta a numerosos comercios. En Santa Cruz y San Julián se suceden los paros parciales. Las tropas enviadas desde el norte comienzan a desembarcar y se dirigen hacia el interior, buscando acabar con el abastecimiento que les proporcionan varios bolicheros, españoles sobre todo, a los huelguistas (Harambour, 1999:163).

Puesto y boliche se alimentan mutuamente y nutren juntos el "virus" del proletariado ambulante, que desborda ahora los límites de la estancia en general, y de la SETF en particular, afectando e incubando en su vecindario los casos Schelkly o Von Heinz. Una carta del cónsul-estanciero Stubenrauch -co-propietario con Von Heinz de la vecina estancia Tapi-Aike- sintetiza el problema del aumento de "pasajeros" en el invierno de 1918, aumento que la política anfitriona de la estancia ya no podía contener:

...me ha llamado mucho la atención la comunicación sobre el tráfico de pasajeros tan considerable, que habían hasta 14 personas con sus respectivos caballos, quedando días en la estancia, donde gastaron, mas de su alojamiento y comida, leña, pasto, etc., todo a discreción.

62 Ya en 1896 José Fiol escribía al joven Mauricio Braun a propósito de los perjuicios que ocasionaba el hotel-boliche ubicado en medio de las estancias de uno y otro (Laguna Romero y Dinamarquero respectivamente): "Para Romero, lo mismo que para esta Estancia, es el Hotel el campo donde con mas frecuencia trabajan los empleados y de preferencia los ovejeros, descuidando tristemente las majadas á su cargo. Muchos de ellos cumplirian con su deber sino encontraran en su camino ese escollo que los detiene. Pocos, muy pocos son los que alojan alli pero en cambio se emborrachan pasajeros, ovejeros y empleados.[...] En Mayo último [Ernest Swinhoe, el bolichero] se permitió abrir o botar nuestro alambre divisorio, como unos veinte metros frente a su casa hotel. Reclamado por mi dijo era para facilitar su negocio con los pasajeros. Este invierno último ha recortado los estacones del alambrado que concluye frente del Hotel en el cerco divisorio con Dinamarquero y ademas ha recortado un buen pedazo de este mismo cerco cuya mitad nos pertenece. La puerta del citado cerco en el camino queda siempre abierta, ó mejor dicho, no existe tal puerta. Los animales de noche y tambien de dia pasan facilmente de uno a otro campo.", carta del 6/10/1896, A.M.R.P.A, "Correspondencia Mauricio Braun". 
Esta hospitalidad tan liberal es un abuso, que va en progreso y no es lícito de tolerarlo, no solamente por el crecido gasto ocasionado a la estancia, sino también por la molestia causada a los empleados, como por ejemplo al cocinero, quien no tiene porque trabajar extra por gente extraña, en los mayores de los casos ociosa, vagando por el campo.- Creo que será necesario restringir este abuso en algo.- No se puede negar el alojamiento por una noche con una comida y el café en la mañana, pero con esto basta, y el viajero tendrá que seguir el viaje en la mañana siguiente, salvo caso fortuito para el cual debe conseguir un permiso especial.- Todo lo demás es extra y debe ser pagado por el viajero, una vez que haya obtenido el permiso.libre.-

1. El primer alojamiento, comida y café

2. Siguientes comidas, almuerzos, etc., debe pagarse a razón de 1.50, de lo cual corresponderá al cocinero 0.50 .

3. Pasto seco, carne, etc., etc debe ser pagado según su valor.

No conozco la tarifa que usan otras estancias, pero creo que en ningún caso es inferior.Aquí se piensa, para restringir el tráfico de gente en el campo en busca de trabajo o por cualquier motivo, establecer libretas que debe de obtener de la Gobernación toda persona que se contrate para el campo, en que se fija el lugar de trabajo, a donde está mandado por cuenta del estanciero contratante.- Parece que el mismo sistema podrá ser introducido en el Territorio de Santa Cruz, y creo que talvez se tratará este punto y otros, en la visita del Sr. Gobernador; de Río Gallegos, que hará por invitación de la Junta de Alcaldes, el 18 de Setiembre próximo.

Esta ordenanza regirá también para Viscachas, Manantiales, etc. ${ }^{63}$

63 Carta a R. Terreros del 17/08/1918, A.I.P, fondo R. Stubenrauch, Copiador de Cartas Tapi Aike, Contaduría, vol. julio 1918 - abril 1921, pp. 38-39. Esta política anfitriona, ya relevada por Fuentes Rabé, al parecer llegó a tener un correlato arquitectónico. Benavides et alter. observan la existencia de edificios que "funcionaban todo el año para los solteros de la estancia y los viajeros ocasionales, pero tenían la capacidad necesaria para el incremento de la demanda en el tiempo de la esquila. Una ley no escrita obligaba a recibir por una noche al viajero, lo que al parecer no siempre se acataba, ya que la estadía se prolongaba como hemos visto a veces sin justificación", (1996: 67-68).
Este devenir multitud del desempleo atravesando por todas partes puestos y boliches indican que el problema del vagabundeo obrero, pese a que en principio funcional a la Explotadora, no podía administrarse en consecuencia; se resistía a entrar en el resto de tráficos que ella controlaba y, en definitiva, permitía asociatividades que le escapaban en todo punto.

No revisitaremos aquí la densa historia de la organización obrera patagónica, fraguada a lo largo del período que venimos estudiando ${ }^{64}$. Bastará señalar simplemente, en qué medida estos itinerarios sin ley, esta circulación subversiva de desempleados, fue vital para el despliegue del movimiento político. En un territorio casi carente de urbes, donde las focos industriales se encontraban a veces a cientos de kilómetros de distancia, el proletariado sin ciudad debió recurrir a nuevas estrategias para su articulación reivindicativa. De hecho, uno de sus ejes se basó en el mantenimiento de una red de información que permitió, por un lado, la colectivización de las experiencias -los abusos ocurridos en una estancia comenzaron a conocerse en las otras- $y$, por otro, la articulación conjunta de acciones la huelga, la más importante de ellas. Los recorridos intermitentes de los correos ecuestres de la Federación Obrera de Magallanes fueron decisivos en este sentido, y la temprana producción y puesta en circulación de prensa proletaria no hizo sino intensificarlos ${ }^{65}$. Las visitas a puestos, boliches y estancias, ya fuese para repartir diarios o para anunciar decisiones sindicales, fueron urdiendo un tejido reivindicativo que terminaría por detener o entorpecer el funcionamiento de la Explotadora. Así lo reportaba T.R.D Burbury a todas las secciones al final de la temporada laboral 1917:

Dear Sir,

With reference to our memorandum of the 12th February, instructing you to allow "cobradores" to collect subscriptions under conditions stated, take note that for the following reasons that permission is hereby withdrawn

64 Ver para el caso santacruceño Lafuente (2002) y para el magallánico Vega (1996) y Harambour (1999).

65 Sobre la relación entre prensa y activismo obrero se puede consultar el notable trabajo de Harambour (1999) sobre la violencia política en Magallanes a comienzos del siglo XX. 
1) Coincident with the arrival of the " $\mathrm{co}$ brador" at Rio Mac the shearers declined to work on the Saturday afternoon, when requested to complete shearing.

2) Coincident with the visit of the "cobrador" to Caleta Josefina, there was a trouble with the shearers

3) The "cobrador" on arrival at our Freezer in Puerto Bories was expelled while attempting to give a socialistic address to workmen during the meal hour.

Under these circumstances, therefore, no representative of any Workmen's Society is to be allowed on the premises.

Yours faithfully

For la SOCIEDAD EXPLOTADORA DE TIERRA DEL FUEGO

\section{T.R.D Burbury General Manager ${ }^{66}$}

La organización obrera, su proselitismo y sus espectros marxistas, muestran la manera cómo uno de los flujos que excedía la vigilancia de la compañía, pero que permanecía hasta entonces en su periferia, llegó a introducirse en el seno mismo de la máquina ${ }^{67}$. Ya no se trataba de cuatreros organizados, de desempleados vagabundos ni mucho menos de indios hambrientos, sino de empleados activos y funcionales que, paralelo a su sumisión a la SETF, parecían enchufarse a otra red -a "discursos socialistas", por ejemplo- que amenazaba ya no sólo la circulación de ovejas sino la marcha general de la Explotadora, en su engranaje más sensible: la fuerza de trabajo.

La SETF intentó por todos los medios destrabar estos nudos colectivizantes que pululaban por su desierto. La extranjerización del

66 Circular del 2/03/1917, A.I.P, fondo SETF, "Copiador de circulares 1913-1918", folio 175.

67 "...Marcos Mancilla, en la Primera Argentina; Lorenzo Suazo y José Carajola, en Bahia Inútil; y tantos otros cuyos nombres se nos escapan por el momento, eran otros tantos propagandistas en pró de la organización sembrados en las distintas estancias de la inmensa lonja patagónica é isla de Tierra del fuego. La organización se habría paso, como desbordado torrente que, cuando ha salido de su cauce amenaza inundar la llanura...", (Iriarte, 1915: 34). "elemento subversivo", no por azar ajustado al régimen raciológico que se aplicaba, fue una de estas estrategias:

Amansados algunos indios, fue fácil reducirlos e incitarlos al trabajo, pero la experiencia confirmó que esta raza era la más huelguista del mundo, el trabajo los cansaba pronto y los sumía en la ociosidad. La pequeña tribu volvió a su campamento y la estancia, a fin de evitar los robos, optó por darles mensualmente la cantidad de cien pesos en víveres. Caitén, el jefe de la familia, rehusó los víveres $y$, por haberse acostumbrado a beber mientras estuvo en contacto con los blancos, solicitó aquella ayuda en dinero efectivo. Poco tiempo más tarde volvieron al trabajo pero, a insinuaciones del indio Hunte, a cada momento se declaraban en huelga. Este cabecilla era sumamente revoltoso y bien puede considerársele el primer huelguista del mundo. Vueltos nuevamente a su vida salvaje, fueron concluyéndose poco a poco y, en la actualidad, parece que ya no existen (Fuentes Rabé, 1923: t.II, 88-89).

Más tarde se sostuvo la idea de que anarquistas, principalmente españoles, e incluso ex-comuneros franceses escapados a la Patagonia ${ }^{68}$, se hallaban en el origen de las revueltas obreras. Lo cierto es que esta clasificación de ociosos / agitadores facilitaría finalmente la alianza estanciero-estatal llamada a disolver el movimiento. En ello Fuentes Rabé, así como los militares argentinos, encontraban un punto convergente con la administración inglesa que en otros aspectos cuestionaban:

...el señor Dick nos manifiesta que es admirador del elemento chileno, al que considera constante, trabajador y ajeno a las revueltas. El año pasado, nos agrega, tenia un porcentaje enorme de estranjeros y las faenas se llevaron a cabo con ciertas dificultades; este año marchamos admirablemente bien y el trabajo llega a su término en medio de la mayor tranquilidad por parte de los trabajadores. Estoy convencido -insinúa- que toda revuelta tiene como base la falta de instrucción en el pueblo; la misma docilidad del elemento chileno, es la causa de que acepten fácilmente y entren a analizar las ideas subversivas que los cerebros

68 Para un discusión sobre esta última afirmación ver Grez (1999). 
desequilibrados se encargan de predicar (Fuentes Rabé, 1923: t.II, 89) ${ }^{69}$.

Pero este intento de aislamiento y clasificación no alcanzó a interrumpir los circuitos obreros que eran, en realidad, un subproducto o un imprevisto, del propio imperio ganadero y su organización disciplinaria. No sería sino el definitivo aterrizaje de las jurisdicciones nacionales, las mismas que no aparecieron para el exterminio ona y que veían entonces el momento de hacer soberanía, con sus respectivos ejércitos y policías, las que, respondiendo al reclamo patronal, cortarían de cuajo las conexiones proletarias. Así, desenchufados los cables subversivos, la SETF recuperó el control de los flujos y reprodujo el desierto biopolítico donde su máquina volvía a ser efectivamente Explotadora.

\section{INTERRUPCIÓN}

La obra de Fuentes Rabé, junto a los documentos que hemos presentado, nos introducen de manera general a las lógicas concretas del trabajo estanciero así como a una variedad de aspectos socioculturales que organizan la producción ovejera. Tanto más cuanto que la documentación compulsada se enmarca en el período de auge de estos poderosos complejos agro-industriales (1890-1920). Frente a la mirada economicista que rige algunos de los estudios sobre la ganadería patagónica, hemos intentado una lectura que sustituye la estática de la dimensión de los campos, de los volúmenes producidos o de las ganancias de sus propietarios, por la dinámica de los flujos de mercancías, de ganado o de trabajo. Lo anterior puesto que procuramos demostrar que, lejos

69 Esta supuesta docilidad ha sido doblemente desmentida, tanto por fuentes obreras como patronales. De hecho, Iriarte afirma que "el trato que dan [en la Explotadora] a los trabajadores los capataces y demas empleados superiores es autoritario, humillante, sobre todo para los chilenos a quienes creen afrentar llamándoles chilotes, esto es, segun ellos, indios", (1915: 36-37) mientras que Trincado niega el carácter subversivo de los extranjeros: "Era notable el espíritu pro empresa de los obreros de origen extranjero que laboraban en la Compañía; también los había croatas, alemanes y escandinavos. Ellos consideraban a la empresa como propia. Estaban siempre preocupados de evitar las pérdidas de animales en los campos, levantando las ovejas caídas, desempantanando vacunos y dando aviso a la administración de cualquier problema que afectara al ganado.”, (2000: 50). del aislamiento en que normalmente se imagina la vida en las estepas patagónicas, las estancias estaban, como pocos lugares del Cono Sur americano, vinculadas a movimientos monetarios y de mano de obra así como a transformaciones político-culturales que trascendían por mucho los límites regionales e incluso nacionales.

De hecho, es posible interrumpir los postulados que presentan, bajo el desierto de la Explotadora, un paisaje social inconexo ${ }^{70}$. Desde luego, la sumisión al régimen ganadero implicaba ciertas restricciones, pero propiciaba también ciertas aberturas o agujeros en la retícula disciplinar. En efecto, hemos visto que el cálculo económico propio del negocio ovejero profitaba de la mano de obra como una fuerza ambulante. Pero de esta necesidad ambulatoria derivó también un contra-poder que, coincidente con el apogeo estanciero, vino a mostrar otra red de relaciones, más acá (a espaldas) o más allá (por encima) de los controles estancieros. Lo notable es que, precisamente la ausencia de "arraigo con la tierra" o la falta de sentimientos nacionales ${ }^{71}$-que Fuentes Rabé se esmera en encontrar ${ }^{72}$-, sugieren ya

70 "Al no existir pueblos-núcleos de desarrollo la desperdigada población rural, desvinculada entre sí y sujeta a dependencia patronal no tuvo ni pudo crear vínculo alguno de arraigo con la tierra, y pasó a ser un conjunto humano transeúnte, desprovisto de todo interés sobre el territorio y su progreso." (Martinic, 1992: 817).

71 Esta carencia era anotada por las mismas autoridades. En agosto de 1920 el gobernador de Magallanes imputaba a los obreros su falta de nacionalismo: "las condiciones impuestas por la Federación de Natales para facilitar su local el 18 de septiembre de 1919 a la comisión organizadora de las fiestas patrias, [...] excluían expresamente del acto la bandera nacional, el himno de la patria, el uniforme militar de Chile y el traje religioso; y la abstención acordada de toda manifestación de adhesión a la patria.", diario La Unión, 31/08/1920, citado en Vega (1996: 232).

72 Como en medio de un mar de propietarios británicos y de extranjeros huelguistas, Fuentes Rabé insiste por última vez en la relación entre nación y subversión, reproduciendo un destello de chilenidad, en el más aplicado de sus paisanos, el ingenioso mecánico Osorio de Springhill: "Cuente señor, allá en el Norte," le dice Osorio, "que el obrero chileno es tan bueno aquí, tan lejos de todo centro poblado y en medio de los ingleses, como cuando trabaja en pleno centro industrial y rodeado de sus compatriotas.", (1923: t.II, 82). Esta caricatura de la vocación nacionalista, habla en realidad del desperfilamiento, o falta, de nacionalismo en la articulación obrera patagónica, lo que obliga, por otra parte, al análisis a alejarse del modelo de "sujeto popular nacional", fundamento de cierta historiografía (Salazar, 1985). 
no una inconsistencia social sino la activación, desde comienzos del siglo XX, de otro tipo de conexiones -la clase obrera- en la superficie sin profundidad -nacional- de nomadismos en otro tiempo dispersos. Pese a la estratificación racial, y por sobre las identidades nacionales, con las que, primero los estancieros, luego los militares y finalmente algunos analistas, han intentado colonizar, pacificar o narrar la Patagonia meridional, la articulación obrera dejó con su tráfico subversivo un subtexto, más coherente de lo que intuimos, interrumpido en los Copiadores de Circulares o en los Libros de Cuentas, cuya huella, así como la de indios o perros salvajes, aún merodea los archivos de la Explotadora.

\section{AGRADECIMIENTOS}

Agradezco a Mirza Ruiz y Jorge Muñoz por su acogida en el Archivo del Instituto de la Patagonia, a don Mateo Martinic por haberme permitido el acceso a la documentación desclasificada, a Alfredo Prieto por los comentarios y sugerencias, y a Alberto Harambour por la interlocución y los papeles ofrecidos.

\section{FUENTES}

- Archivo del Instituto de la Patagonia, fondo Sociedad Explotadora de Tierra del Fuego.

- Archivo del Instituto de la Patagonia, Copiador de Cartas Cerro Palique, 1897-1907.

- Archivo del Instituto de la Patagonia, fondo R. Stubenrauch, Copiador de Cartas Tapi Aike, Contaduría, vol. julio 1918 - abril 1921.

- Archivo del Museo Regional de Punta Arenas, Correspondencia Mauricio Braun.

\section{BIBLIOGRAFÍA}

BANDIERI, Susana, 2005. Del discurso poblador a la praxis latifundista: La distribución de la tierra pública en la Patagonia., Mundo Agrario, 6, n. 11.

BARBERIA, Elsa, 1974. Nacimiento y evolución de una de las primeras estancias del sur de Santa Cruz "MarkatchAike" (1896-1929), Karukinka, 7: 68-83.

BAYER, Osvaldo, 2002. La Patagonia rebelde, Buenos Aires: Planeta.

BENAVIDES, J., M. Martinic, M. Pizzi \& M. P. Valenzuela, 1999. Las estancias magallánicas. Un modelo de arquitectura industrial y ocupación territorial en la zona austral, Santiago: Ed. Universitaria.

BORRERO, José María, 1989. La Patagonia trágica. Asesinatos, piratería y esclavitud, Ushuaia: Zagier.

CALDERÓN, Julio, 1936. Historia de la Industria Ganadera en el Territorio de Magallanes, Ministerio de Agricultura.

CHILDS, Herbert, 1997. El Jimmy, bandido de la Patagonia, Punta Arenas: UMAG.

CHONCHOL, Jacques, 1995. Systèmes agraires en Amérique Latine. Des agriculteurs préhispaniques à la modernisation conservatrices, Paris: IHEAL.

DELEUZE, Gilles y Félix GUATTARI, 1980. Mille Plateaux, Paris: Minuit.

DÍAZ BAHAMONDE, José, 1994. Un reencuentro con "la hez de la aldea". Vida popular en Punta Arenas, 1877-1920, Santiago: Tesis para optar al grado de Licenciado en Historia, U. Católica de Chile.

DURÁN, Fernando, 1951. Sociedad Explotadora Tierra del Fuego, Valparaíso: SETF.

EIZAGUIRRE, José Manuel, 1897. Tierra del Fuego. Recuerdose é impresiones de un viaje al extremo austral de la República, precedido de una introducción por el ingeniero Julio Popper, Córdoba: La Velocidad.

FUENTES RABÉ, Arturo, 1923. Tierra del Fuego, Imprenta Central E. Lampert.

GREZ TOSO, Sergio, 1999. Los ex-communards en Magallanes. Realidad y mito en nuestra historiografía, (ed.) Actas IV Congreso de Historia de Magallanes, Punta Arenas: UMAG, 7-15.

HARAMBOUR ROSS, Alberto, 1999. El movimiento obrero y la violencia política en el territorio de Magallanes, 1918-1925, Santiago: Tesis para optar al grado de Licenciado en Histora, U. Católica de Chile.

HOBSBAWM, Eric J. 1977, Histoire économique et sociale de la Grande-Bretagne. Tome 2, Paris: Seuil.

IRIARTE, Gregorio, 1915. La organización obrera de Magallanes, Punta Arenas: Imprenta "El Trabajo".

LAFUENTE, Horacio, 2002. Una sociedad en crisis. Las huelgas de 1920 y 1921, Buenos Aires: C.I.E..N.

MARTINIC, Mateo, 1973. Panorama de la colonización en Tierra del Fuego entre 1881 y 1900, Anales del Instituto de la Patagonia, IV, N. 1-3: 5-69.

-1985. Última Esperanza en el tiempo, Punta Arenas: Universidad de Magallanes.

-1989, El genocidio Selknam: nuevos antecedentes, Anales del Instituto de la Patagonia, vol. 19: 2328.

-1992, Historia de la Región Magallánica, Punta Arenas: Universidad de Magallanes. 
-2001. El ordenamiento rural en Magallanes, 1894-1973: la dirección y el manejo de las grandes estancias, Academia Chilena de la Historia (ed.) Vida rural en Chile durante el siglo XIX, Santiago: Academia Chilena de la Historia, 175-200.

-2007. Los británicos en la región magallánica, Valparaíso: UMAG-UPLA.

PAYRÓ, Roberto J., 1898. La Australia argentina. Excursión periodística á las costas patagónicas, Tierra del Fuego é Isla de los Estados, con una carta-prólogo del General Bartolomé MItre, Buenos Aires: Imprenta de "La Nación".
SALAZAR, Gabriel, 1985. Labradores, peones y proletarios. Formación y crisis de la sociedad popular chilena del siglo XX, Santiago: SUR.

SPEARS, John R., 1895. The Gold Diggings of Cape Horn, New York: G.P. Putnams's Sons / The Knickerbocker Press.

TRINCADO, Roberto, 2000. Seis caballos y un Winchester, Santiago: Patagonia.

VEGA DELGADO, Carlos, 1996. La masacre de la Federación Obrera de Magallanes, Punta Arenas: Imprenta Atelí.

YRARRÁZAVAL, 1910. José Miguel, El ganado lanar en Magallanes, Santiago: Imprenta Barcelona. 